
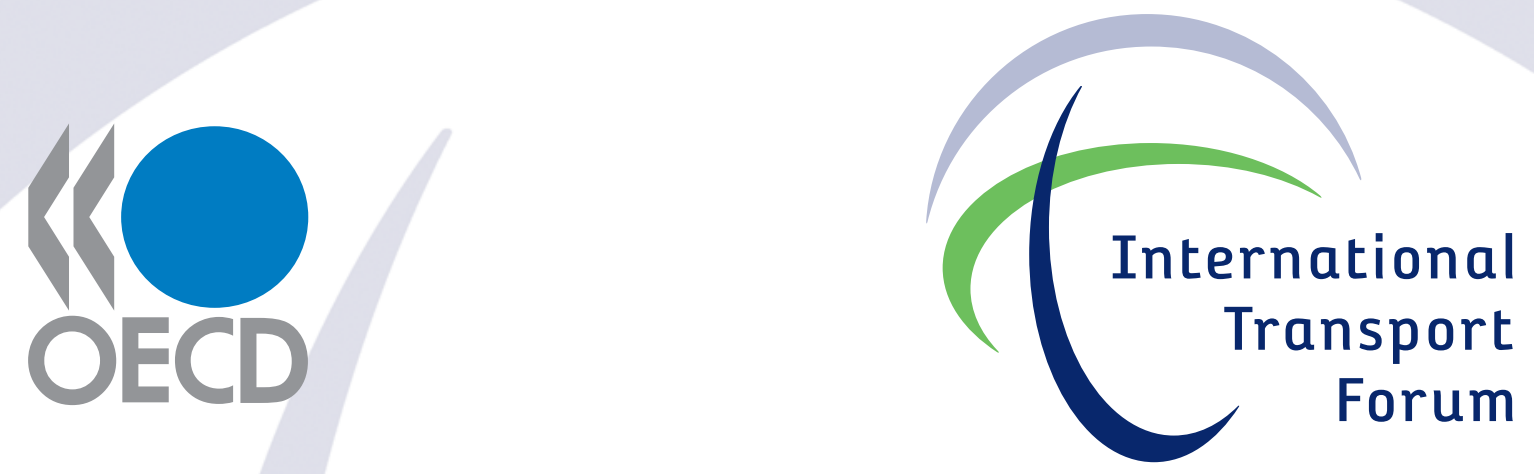

J OINT TRANSPORT RESEARCH CENTRE

$$
\begin{array}{r}
\text { Discussion Paper } \mathcal{N o .} \text { 200q-11 } \\
\text { May 200q }
\end{array}
$$

\title{
Greenhouse Gas Emissions
}

Reduction Potential from

\section{International Shipping}

Philippe CRIST

J oint Transport Research Centre of the OECD and the International Transport Forum 

Discussion Paper No. 2009-11

Greenhouse Gas Emissions Reduction Potential from International Shipping

\section{Philippe CRIST $^{1}$}

Joint Transport Research Centre of the OECD and the International Transport Forum

May 2009 
The International Transport Forum is an inter-governmental body within the OECD family. The Forum is a global platform for transport policy makers and stakeholders. Its objective is to serve political leaders and a larger public in developing a better understanding of the role of transport in economic growth and the role of transport policy in addressing the social and environmental dimensions of sustainable development. The Forum organises a Conference for Ministers and leading figures from civil society each May in Leipzig, Germany.

The members of the Forum are: Albania, Armenia, Australia, Austria, Azerbaijan, Belarus, Belgium, Bosnia-Herzegovina, Bulgaria, Canada, Croatia, the Czech Republic, Denmark, Estonia, Finland, France, FYROM, Georgia, Germany, Greece, Hungary, Iceland, Ireland, Italy, Japan, Korea, Latvia, Liechtenstein, Lithuania, Luxembourg, Malta, Mexico, Moldova, Montenegro, Netherlands, New Zealand, Norway, Poland, Portugal, Romania, Russia, Serbia, Slovakia, Slovenia, Spain, Sweden, Switzerland, Turkey, Ukraine, the United Kingdom and the United States. The Forum's Secretariat is located in Paris.

\section{Joint Transport Research Centre}

The OECD and the International Transport Forum established a Joint Transport Research Centre (JTRC) in 2004. The Centre conducts co-operative research programmes addressing all modes of transport to support policy making in Member countries and contribute to the Ministerial sessions of the International Transport Forum.

\section{JTRC Discussion Papers}

The JTRC Discussion Paper Series makes economic research commissioned or carried out at the Joint Transport Research Centre available to researchers and practitioners. The aim is to contribute to the understanding of the transport sector and to provide inputs to transport policy design. The Discussion Papers are not edited by the JTRC and they reflect the author's opinions alone. They can be downloaded from:

http://www.internationaltransportforum.org/jtrc/DiscussionPapers/jtrcpapers.html

The International Transport Forum's website is at: http://www.internationaltransportforum.org/

For further information on the Discussion Papers and other JTRC activities, please email: itf.contact@oecd.org 


\section{Summary and Key Messages}

In this paper, we discuss the greenhouse gas emission reduction potential from international shipping. Drawing from the International Maritime Organization's most recent assessment of maritime greenhouse gas emissions and other sources, we investigate the current level of emissions from international maritime activity and look at factors influencing future emission levels such as projected activity levels, GHG-reducing technology options and the rate of their uptake, operational measures - foremost speed reduction - and fuel switching. We do not discuss the marginal abatement costs of maritime GHG-reduction measures - with the exception of speed reduction - due to insufficient evidence. Finally, we discuss factors that may influence international responses to maritime GHG reduction policies, though these are discussed more thoroughly in a companion paper (Kågeson, 2009).

$\mathrm{CO} 2$ emissions from maritime transport are larger than has previously been estimated

The IMO finds that international maritime activity accounted for $843 \mathrm{Mt}$ of CO2 in 2007 or $45 \%$ more than previous emission estimates from marine bunkers. This finding, for illustrative purposes, places 2007 international shipping emissions between the 2005 national emissions of India and Germany. International shipping accounts for approximately $2.7 \%$ of world $\mathrm{CO} 2$ emissions from fossil fuel combustion with all shipping activity (fishing, domestic and international) representing approximately $3.3 \%$ of total $\mathrm{CO} 2$ from fuel combustion.

Despite projected efficiency improvements, the IMO projects that $\mathrm{CO} 2$ emissions from international maritime activity will grow through 2050 though this growth may significantly slowed through uptake of fuel efficient technologies and operating procedures

Despite expected energy efficiency improvements, the IMO projects that $\mathrm{CO} 2$ emissions from international shipping will grow by $10-26 \%$ by 2020 and $126-218 \%$ by 2050 . Realizing maximum potential efficiency improvements coupled with significant speed reductions and more intensive use of low-carbon fuels can lead to stabilized or slightly decreasing CO2 emissions from international shipping but these developments are unlikely to occur without significant interventions.

The current economic recession will not significantly impact long-term trends in the sector, though it will have impacts on the rate of fleet turn-over in the short-run which will slow the uptake of fuel efficient technology. This impact may be countered by lower $\mathrm{CO} 2$ emissions resulting from reduced shipping activity

The United Nations Conference on Trade and Development estimates that world seaborne trade reached $49,374,000$ tonne kilometres in 2006. Total maritime trade has doubled from 1985 to 2007, total containerised trade has grown eight-fold over the same period and currently represents $16 \%$ of all maritime trade by weight (and a much larger share by value).

The impact of the economic downturn of 2008-2009 will be to reduce overall maritime trade activity leading to lower $\mathrm{CO} 2$ emissions than had been previously forecast. At the same time, this reduction in activity will likely be accompanied, but not offset, by a slower rate of uptake of fuel efficient technologies and designs due to reduced fleet turnover in the short- to medium-term. Lower oil prices as a result of softening demand will further reduce the fuel efficiency imperative for newbuilds while, at the same time, lowering pressure to implement operational fuel savings. Under the current market and regulatory structure of maritime transport, it is not at all clear that $\mathrm{CO} 2$ reduction imperatives will in any way replace fuel cost imperatives -- it is therefore highly unlikely that maritime fuel efficiency will increase at a higher rate than has been historically observed for the sector absent additional policies. Overall, the $\mathrm{CO} 2$ impact from reduced economic activity will likely more than offset the $\mathrm{CO} 2$ 
impact from slower uptake of fuel efficient designs and practices. "Business-as-usual" emissions from international maritime transport are likely to track below rather than above the current baseline projections of the IMO.

Maritime transport has steadily improved its energy efficiency though there still remain significant energy savings and $\mathrm{CO} 2$ reduction opportunities

The overall potential $\mathrm{CO} 2$ emission reductions from current vessel design strategies for newbuilds can be estimated to be in the range of 5-30\%. Technical retrofit and maintenance strategies on existing vessels can potentially reduce $\mathrm{CO} 2$ emissions from the existing fleet by $4-20 \%$ while operational strategies might potentially reduce fuel use and CO2 emissions by as much as $40 \%$. Combined technical and operational measures have been estimated to potentially reduce $\mathrm{CO} 2$ emissions by up to $43 \%$ per tonne-kilometre by 2020 and by up to $63 \%$ per tonne kilometre by 2050.

Speed reduction, especially for fast vessels, represents an important operational measure that can save fuel and limit $\mathrm{CO} 2$ emissions at relatively low cost and little effort

While not free, speed reduction, especially for high powered and high speed container vessels can lead to significantly reduced fuel consumption and $\mathrm{CO} 2$ emissions especially as there is evidence that a real gap exists between optimum travel speeds and actual speeds. Optimum vessel speeds from the perspective of fuel consumption are not necessarily the slowest speeds when all factors are considered. Speed reduction must be balanced with other commercial or operational imperatives that may prove more important than reducing fuel costs and $\mathrm{CO} 2$ emissions. Preliminary modelling indicates that the marginal abatement costs of speed reduction for container vessels may be in the order of $\$ 20-\$ 50$ per tonne of CO2 (for a speed reduction in the order of $10 \%-25 \%$ and a fuel price of $\$ 300 /$ tonne, though the real costs faced by commercial operators may be lower.

Vessel owners and operators make decisions that impact $\mathrm{CO} 2$ emissions based on a variety of factors of which improved fuel consumption may only play a minor role - especially when fuel prices are low and contractual arrangements dilute responsibility for designed versus achieved fuel consumption

Many maritime trades are characterised by a principal agent problem where the parties responsible for designing (and, to a lesser extent, operating) a vessel and those responsible for paying for fuel are not the same. Depending on the particular charter party contract, fuel costs may be borne by the owner, the vessel operator or the cargo owner and responsibility for fuel costs may even change whilst the vessel is underway. While ship owners are under pressure to specify ship technologies for their newbuilds that are competitive under prevailing market conditions and expected energy prices, the reality is that the lack of direct responsibility for ship fuel costs and the pressure of other commercial criteria mean that many newbuilds are characterised by less-than-full potential fuel economy.

The outcome of negotiations currently underway at the IMO in preparation for COP 15 is uncertain but the overall impact of measures decided in Copenhagen will ultimately hinge on the extent to which they impact fuel use from the current fleet as well as newbuilds, the extent to which they apply to all flag states and/or trading vessels and the extent to which instruments are made mandatory

Slow fleet turnover means that operational and maintenance-related efficiency gains will likely dominate over the short- to medium-term. Accordingly, measures such as the IMO's Energy Efficiency Operational Index and, ultimately, economic instruments such as a global fuel levy or emission trading need to be implemented if significant emission reductions from current fleet activity is to be achieved over the next decades. In addition, the $\mathrm{CO} 2$ reduction 
impact of regulatory measures such as the Energy Efficiency Design Index can be greatly enhanced by conditioning these to strong incentives or or making them mandatory. Finally, given that over two thirds of the world's international maritime fleet is registered in non Annex 1 countries while, conversely, two-thirds of the world's fleet is owned by nationals of Annex 1 countries, action undertaken at the IMO following COP 15 should target all vessels or all countries in order to deliver real $\mathrm{CO} 2$ reductions. 


\section{Greenhouse Gas Emissions from Shipping}

Maritime transport is largely dependent on Heavy Fuel Oil (HFO) which accounts for approximately $77 \%$ (IMO, 2007) of maritime transport fuel used and almost all fuel used by ocean-going ships. Vessels engaged in coastal trips use either HFO or lighter marine distillate oil ${ }^{2}$. HFO is a visquous residual product remaining at the end of the crude oil refining chain and as such, contains an elevated share of impurities (e.g. oxides, sulphur and water). These must be removed through centrifuges/filters and the fuel's viscosity must be reduced via pre-heating to allow combustion. Nonetheless, it is an available and relatively cheap refinery by-product and well-suited for use in current large marine engines -- hence its popularity.

The climate-forcing impacts from shipping are linked to the by-products of HFO, and to a lesser extent, MDO combustion. These by-products are:

Carbon Dioxide (CO2) which has a direct, global and long-lasting climate forcing impact,

Black carbon (BC) which also has a direct but somewhat lesser and more regionally constrained impact than $\mathrm{CO} 2$. Black carbon's warming impact is linked mainly to surface deposition and heat absorption in snow- and ice-covered areas (e.g. the poles and highaltitude glaciers).

Nitrogen Oxides (NOx) is formed by high temperature combustion in ship engines and acts as a precursor to tropospheric ozone (O3), itself a powerful greenhouse gas. In certain conditions however, NOx emissions can lead to a rise in methane $(\mathrm{CH} 4)$ destruction (see box 1 ) and can thus contribute to reduced atmospheric warming.

Sulphur dioxide (SO2). SO2 is transformed into sulphate (SO4) in the atmosphere which is thought to have a net cooling impact on climate.

Carbon Monoxide ( $\mathrm{CO}$ ) is a precursor to both tropospheric ozone and methane.

Of these, $\mathrm{CO} 2$ has by far the largest long term impact and the remainder of this chapter will focus on this greenhouse gas, although, as pointed out in Box 1, the climate impact of other HFO and MDO by-products should not be ignored.

According to IEA data, international maritime activity (calculated by the sale of fuel to vessels whose next port-of-call is outside the country) accounted for $543.4 \mathrm{Mt}$ of $\mathrm{CO} 2$ emissions from fuel combustion in 2005. Figures on fuel use and emissions from international maritime activity, however, are less accurate under current IEA reporting requirements than for road and rail. International marine "bunker" fuel statistics were not conceived to represent the total energy used by ships engaged in global commerce. Rather, these data were designed to differentiate fuel stocks that are covered by the allocation regime of the IEA's emergency oil sharing system and those that are not. Some researchers find that that this leads to an erroneous estimate of maritime fuel use. An error ranging between $25 \%$ for cargo ships and a factor of two for the world fleet can be found by contrasting international maritime transport fuel sales data with activity-based estimates of ship energy requirements (Corbett, Koehler, $2004,2007)^{3}$. 
Bottom-up studies have sought to estimate maritime fuel consumption and $\mathrm{CO} 2$ emissions by modelling the world fleet and accounting for its activity. Some of this work has incorporated detailed manufacturer's data on engines, rated power, operating cycles, actual vessel travel patterns and overall vessel energy consumption (Corbett, Eyring 2007 and IMO 2007), others have looked at historical factors that have had an impact on shipping activity and used fleet-average models (Endresen et al. 2007). Both types of estimates find higher CO2 emissions than the IEA.

In October 2008, the International Maritime Organization Marine Environment Protection Committee (MEPC) considered a study it commissioned to update its official estimate of fossil fuel use and $\mathrm{CO} 2$ emissions from international maritime activity. The study "Greenhouse Gas Emissions from Ships: Phase 1 Report "-- brought together all of the leading experts in bottom-up activity-based modelling of the world shipping fleet. They suggest a consensus estimate of CO2 emissions from all ocean ship activity of $1019 \mathrm{Mt}$ in 2007 of which $843 \mathrm{Mt}$ result from international shipping (see table below). The figure for international shipping represents 45\% more than the study's estimated IEA 2007 CO2 emissions from marine bunkers. This finding, for illustrative purposes, places 2007 international shipping emissions between the 2005 national emissions of India and Germany. The new estimate of $\mathrm{CO} 2$ from international shipping accounts for approximately $2.7 \%$ of world $\mathrm{CO} 2$ emissions from fossil fuel combustion with all shipping activity (fishing, domestic and international) representing approximately $3.3 \%$ of total $\mathrm{CO} 2$ from fuel combustion. 
Table 1. Consensus estimate of 2007 CO2 emissions for Shipping (Mt CO2)

\begin{tabular}{lllll|l} 
& $\begin{array}{l}\text { Low } \\
\text { bound }\end{array}$ & Consensus & $\begin{array}{l}\text { High } \\
\text { bound }\end{array}$ & $\begin{array}{l}2007 \\
\text { est. } \\
\text { IEA* }\end{array}$ \\
\hline $\begin{array}{l}\text { Total Shipping Emissions } \\
\text { Less fishing (activity-based) }\end{array}$ & $\begin{array}{l}\text { (54 } \\
(58)\end{array}$ & $\begin{array}{l}1019 \\
(65)\end{array}$ & $\begin{array}{l}1224 \\
(74)\end{array}$ & $\begin{array}{l}713 \\
(20)\end{array}$ \\
\hline $\begin{array}{l}\text { Total International and Domestic (activity- } \\
\text { based) }\end{array}$ & 796 & 954 & 1150 & 693 \\
$\begin{array}{l}\text { Less IEA domestic shipping (Marine Bunker } \\
\text { fuel-based) }\end{array}$ & $(111)$ & $(111)$ & $(111)$ & $(111)$ \\
\hline \begin{tabular}{l} 
International Shipping (Hybrid estimate) \\
\hline
\end{tabular} & 685 & 843 & 1039 & 582 \\
\hline
\end{tabular}

Source: Buhaug, $\varnothing$, et al, 2008, *Estimated by Buhaug, $\varnothing$, et al

\section{Box 1. Assessing Radiative Forcing from Transport Activity}

While studies assessing overall emissions from transport activity are numerous, and some studies have sought to assess the climate forcing of aviation (e.g. IPCC 1999, Sausen 2005), very few have attempted to assess the combined climate forcing impact of the sector as a whole. One such study by the Centre for International Climate and Environmental ResearchOslo (CICERO) has done so (Fuglestvedt et al. 2007). It finds that for past transport emissions (1875-2000), RF from CO2 dominates with a total contribution equal to roughly $15 \%{ }^{1}$ of the total anthropogenic CO2 forcing over the same period $(230 \mathrm{~mW} / \mathrm{m} 2)$. The corresponding figures for road transport are $10 \%$ and $150 \mathrm{~mW} / \mathrm{m} 2$. The second largest component of man-made climate forcing from transport is from tropospheric ozone where all transport sectors combined represent up to 31\% of the total anthropogenic O3 forcing from 1875 to 2000 . As with CO2 forcing, the road sector represents the principal source of O3 forcing, with aviation and shipping together representing approximately half of the roadbased $\mathrm{O} 3$ forcing.

Accounting for all positive and negative forcings for the period 1875-2000, the road sector has had the largest positive forcing (e.g. a warming) impact, followed by aviation and rail. Shipping is found to have had a net negative forcing (e.g. a cooling) impact over the same period - largely due to the direct and indirect cooling impact of sulphur emissions and due to the contribution of shipping NOx emissions to $\mathrm{OH}$ formation and ensuing $\mathrm{CH} 4$ reduction (see below).

Figure 1-16 displays the estimated integrated forcing of year 2000 emissions by gas and by transport sector. Figure 1-16-A shows the integrated global mean RF ( $\mathrm{mW} / \mathrm{m} 2 / \mathrm{yr})$ at the 100year time horizon. Figure 1-16-B shows the integrated mean net RF per sector normalised to the values of road transport at 20-, 100- and 500-year time horizons consistent with the IPCC's Fourth Assessment Report. Uncertainty ranges are displayed as whiskers corresponding to one standard deviation.

As with the historical outlook, forcing from current road transport $\mathrm{CO} 2$ emissions dominate, followed by aviation, shipping and rail. However, the figure and the report on which it is based uses an estimate of shipping fuel consumption and emissions (Endresen et al., 2007) that is lower than more recent activity-based inventories (IMO 2008) and might, therefore, underestimate the $\mathrm{CO} 2$ forcing for shipping. 
Much as in the historical outlook, forcing from ozone represents the second largest component of transport-related climate forcing, with the largest contribution coming from road transport followed by shipping, aviation and rail. The assessment of radiative forcing from current transport emissions confirms the historical assessment in that road, aviation and rail have positive forcing impacts over all three time horizons whereas shipping has a net cooling impact over the 20-year and 100-year horizons, again, largely due to the direct and indirect cooling impact of sulphur emissions and due to the contribution of shipping NOx emissions to $\mathrm{CH} 4$ reduction.

The net cooling impact the study finds for shipping requires an explanation. Emissions of NOx can have either a cooling impact by reducing $\mathrm{CH} 4$ (through the formation of $\mathrm{OH}$ ) or a warming impact (through the formation of $\mathrm{O} 3$ when combined with $\mathrm{CO}$ and VOC's). Shipping emissions have high NOx to $\mathrm{CO}$ and high NOx to VOC ratios and take place in a low NOx environment. This means that a smaller share of NOx is converted into $\mathrm{O} 3$ and a relatively larger share of $\mathrm{NOx}$ is converted to $\mathrm{OH}$ which then breaks down $\mathrm{CH} 4$. In short, because of the nature and location of shipping NOx emissions, the cooling impact of $\mathrm{CH} 4$ removal is greater than the warming impact of $\mathrm{O} 3$ formation.

Marine fuels currently contain a relatively high share of sulphur which results in postcombustion emissions of sulphur dioxide $\left(\mathrm{SO}_{2}\right)$. SO2 is then transformed into sulphate (SO4) in the atmosphere. Sulphate particles have three cooling impacts of climate. They reflect solar radiation, they change the composition of cloud cover such that clouds reflect more solar radiation and they increase the extent and duration of ocean cloudiness - though it should be noted that the scientific understanding of these indirect phenomena is poor.(Torvanger, Bogstrand, Skeie, \& Fuglestvedt, 2007).

Incomplete combustion of "dirty" marine fuels also leads to the emission of particulate matter ("black carbon") which, contrary to sulphur, has a positive warming impact principally via deposition on sea ice and land snow cover (e.g. glaciers) which leads to increased absorption of solar energy, warming, melting and loss of albedo-contributing surface area. As snow cover recedes, land and sea masses absorb and retain more solar heat contributing to atmospheric warming.

Aviation emissions have a lower NOx to $\mathrm{CO}$ and a lower NOx to VOC ratio than shipping which indicates a greater potential for aviation NOx to be converted to $\mathrm{O} 3$ rather than $\mathrm{OH}$. Aviation emissions resulting from taxiing and take-off can be assimilated to other groundlevel NOx emissions and contribute principally to ground-level O3. Sub-sonic aircraft NOx emissions in the upper troposphere and lower stratosphere (e.g. less than 18kms) also tend to increase tropospheric ozone rather than break down $\mathrm{CH} 4$ - this is especially true immediately above the tropopause where a large share of aviation emissions take place (see Figure 1-17). This means that the warming impact from aviation-induced $\mathrm{O} 3$ creation is more than the cooling impact of aviation-induced CH4 destruction (IPCC 1999, Sausen 2005). Furthermore, $\mathrm{O} 3$ is less readily broken down at and above the tropopause and thus tends to have a longer life there than ground-level O3, compounding its climate impact (Rogers, 2002). These $\mathrm{NOx}-\mathrm{O} 3-\mathrm{OH}$ reactions are also dependent on the season, latitude and ambient temperature and solar radiance. A recent evaluation of aviation-related climate forcing (Sausen et al., 2005) finds that the instantaneous forcing from NOx-induced $\mathrm{O} 3$ and contrail formation is about twice as high as the $\mathrm{CO} 2$ forcing alone. The non-CO2 forcing from aviation diminishes over time as the relative importance of the $\mathrm{CO} 2$ component increases. 


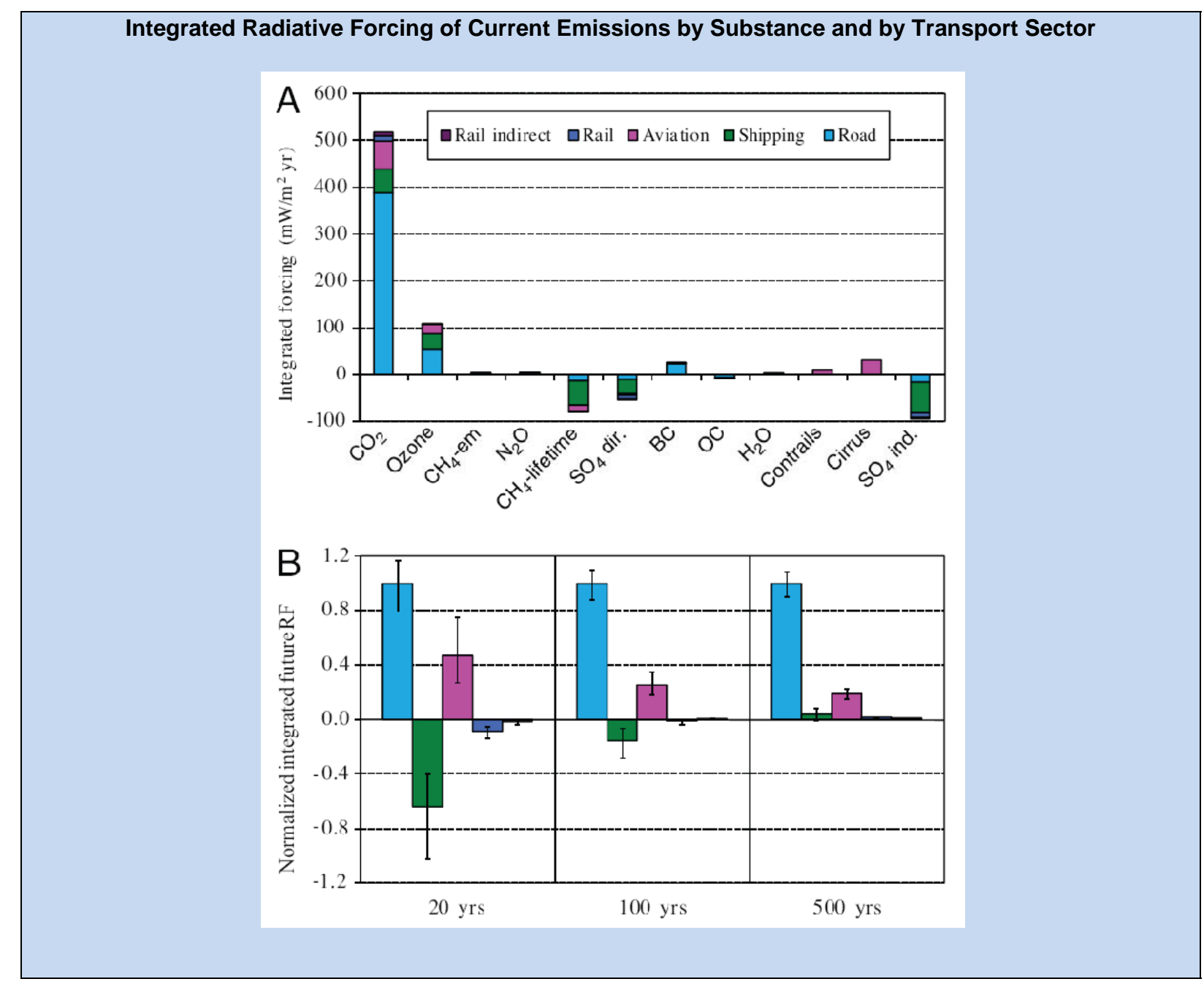


Figure 1. Fuel Use (thousand tonnes) by Vessel Category 2007 (excluding fishing, service and offshore supply vessels)

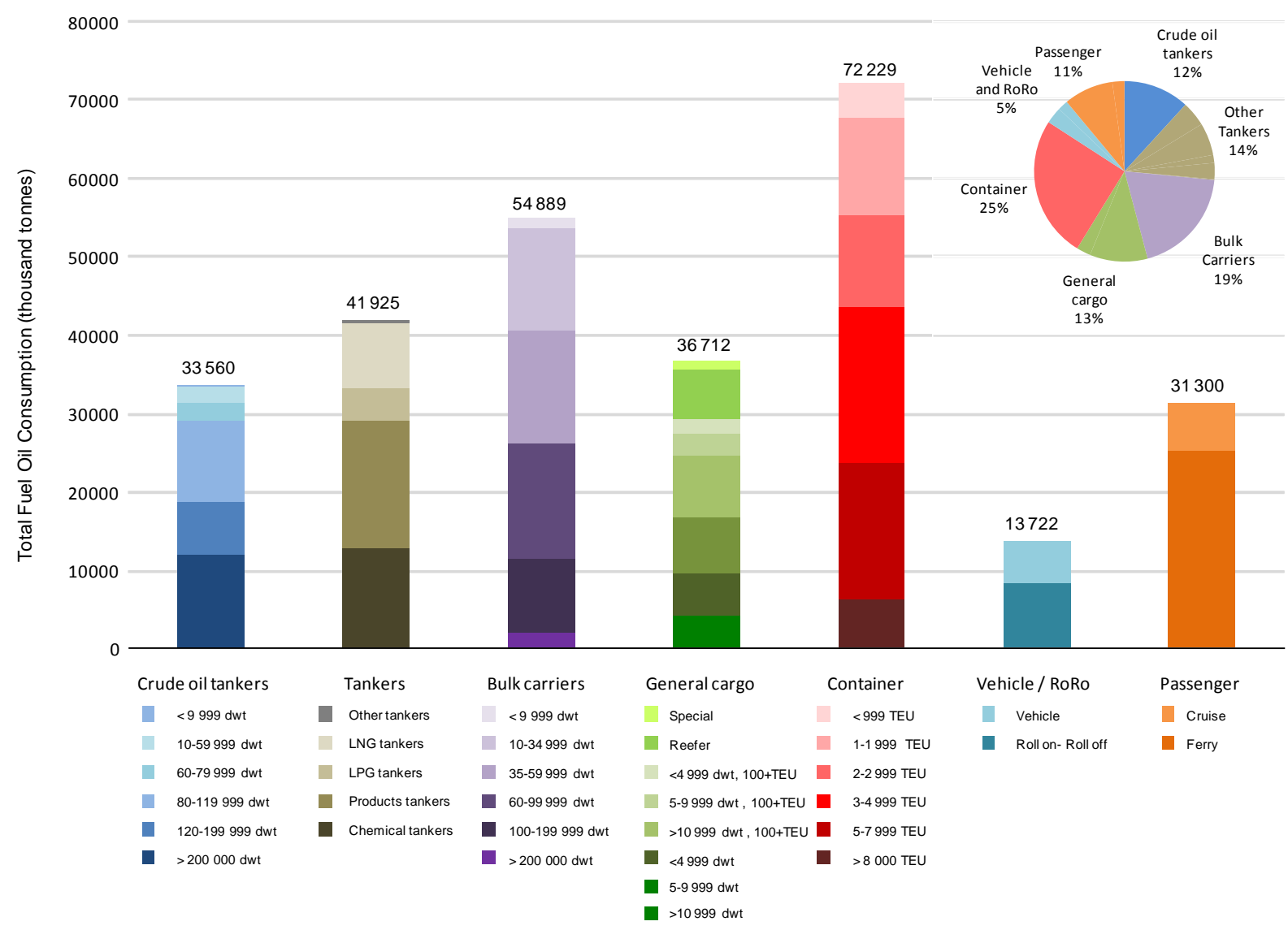

Source: Source: Buhaug, $\varnothing$, et al, 2008

Fuel use (and, by proxy, CO2 emissions) by vessel category is largely dominated by freight activity: passenger vessels account for only $11 \%$ of the total (excluding fishing, service and offshore supply vessels). Container vessels dominate representing $25 \%$ (for 4138 vessels) of the total while all crude and other tanker vessels combined represent $28 \%$ of the total - but with a much higher number of ships (12 930 vessels). This can be explained by the more powerful engines and higher operating speeds required by this segment's particular duty cycle characteristics.

International maritime activity has grown significantly and, for several key sectors, is projected to continue to grow strongly in the future. The United Nations Conference on Trade and Development estimates that world seaborne trade reached 49,374 million tonne kilometres in 2006 (UNCTAD, 2007). Figure 2 displays historic levels of maritime activity (measured in tonnes delivered from 1985 to 2007 . Total maritime trade has doubled from 1985 to 2007, total containerised trade has grown eight-fold over the same period and currently represents $16 \%$ of all maritime trade by weight (and a much larger share by value). In aggregate, however, energy use per tonne delivered ${ }^{4}$ by sea has followed a slightly

4 Here measured by proxy using $\mathrm{CO} 2$ emissions from international maritime bunkers divided by the total number of tonnes delivered in any given year. 
decreasing trend from 1985 to 2007 with the advent of more efficient engines and vessels despite much higher volumes of energy intensive containerised trade.

Growth in international maritime transport ${ }^{5}$ activity has generally followed, and oftentimes outstripped GDP growth (see Figure 3). While international trade continues to drive maritime activity, the latter is no longer principally driven by output in OECD countries but, rather, from many emerging export markets such as China. In 2006, world merchandise trade grew by $8 \%$ - double the rate of world GDP growth - contributing to robust growth in container trades that carry much of the world's manufactured output between continents as well as much of the value of seaborne trade (Drewry Shipping Consultants estimate that over $70 \%$ of the value of world seaborne trade is currently carried by maritime container).

Maritime trade will continue to grow in tandem with rising demand for oil, coal, steel and other primary resources by China and, to a lesser extent, India. This demand has already led to more distant sourcing of these resources (e.g. in 2007-2008, China had started to source iron ore from Brazil and Africa as Australian output had reached a plateau) leading to increased GHG emissions. China, before the economic crisis of 2009 , had recently become a net importer of coal which, as a knock-on effect, will lead past importers of Chinese coal in the region such as Japan, Korea, Chinese Taipei turn to more-distant Australian and Indonesian coal once recovery gets underway and thus increase GHG emissions for regional maritime coal deliveries (which represent a major share of bulk shipping activity).

Figure 2. Historic Trends in Maritime Transport Volumes and Relative CO2 Emissions

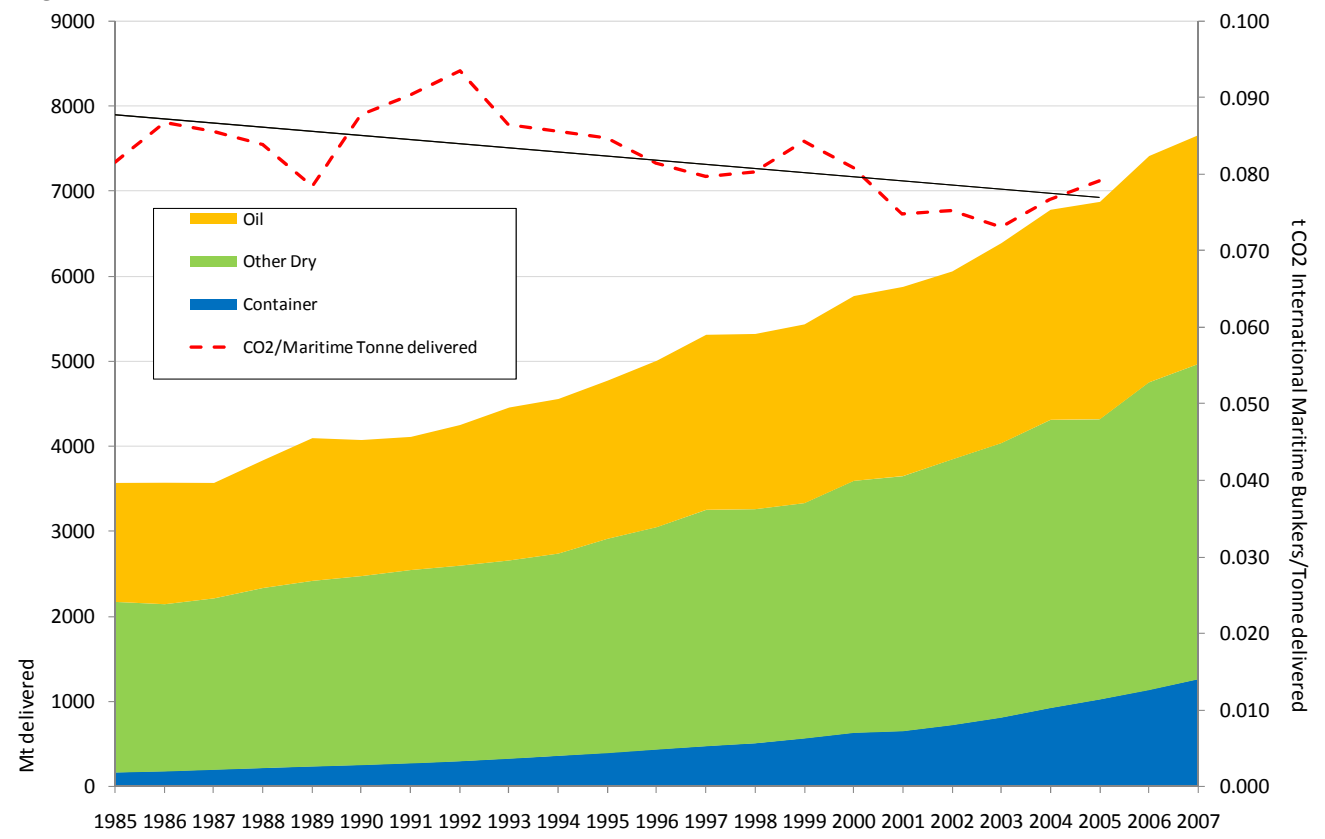

Source: Clarksons, Global Insight, Drewry and IEA

\footnotetext{
${ }^{5}$ UNCTAD's “Review of Maritime Transport, 2007" serves as the basis for this section.
} 
Figure 3. Growth in Maritime Trade, World Trade and GDP (Indexed): 1994-2006

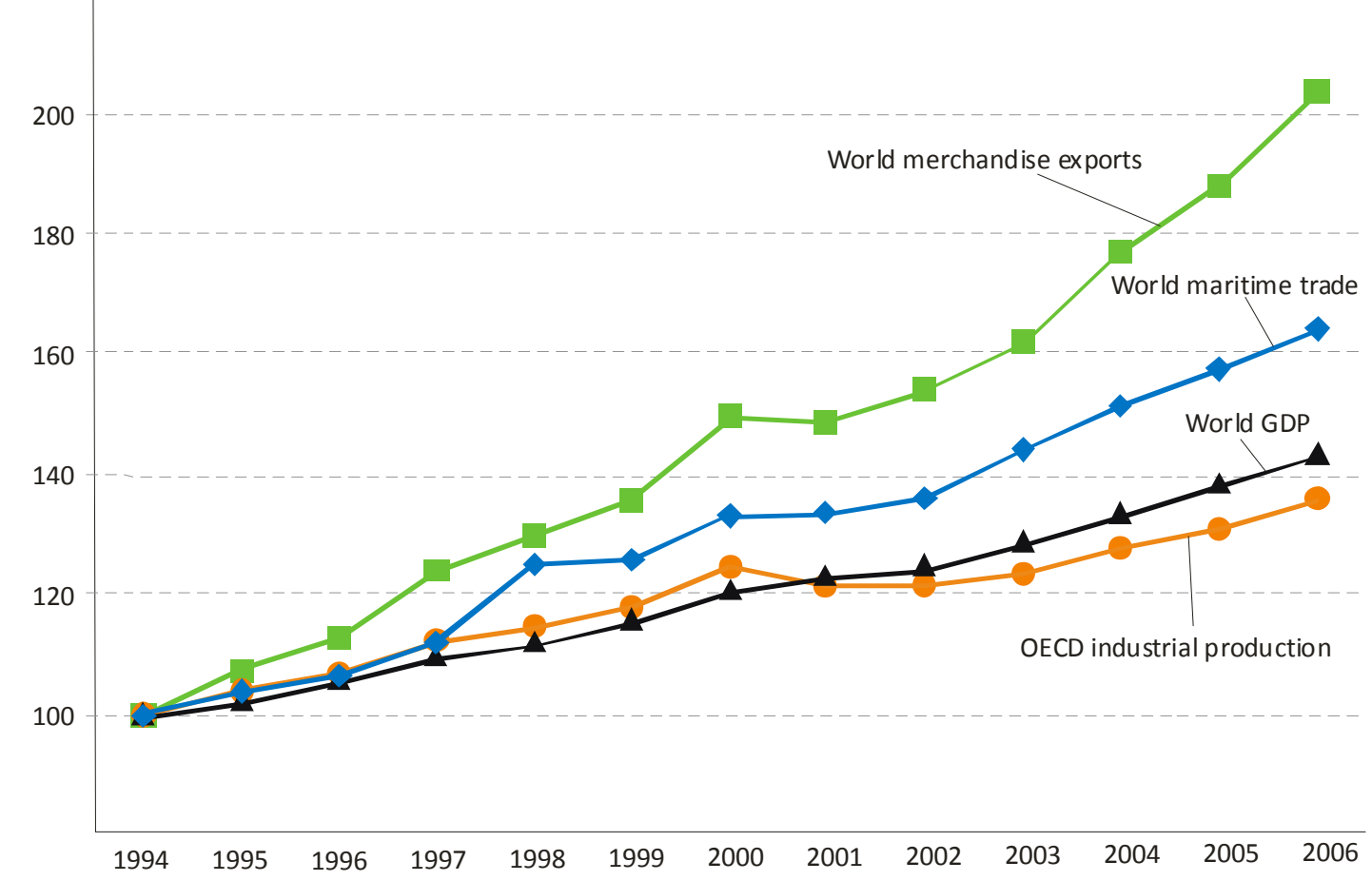

Source: UNCTAD, Review of Maritime Transport, 2007

Figure 4. Global Maritime Traffic and CO2 Emissions 2001 (CO2 as metric tonnes $\mathrm{C}$ per grid cell)

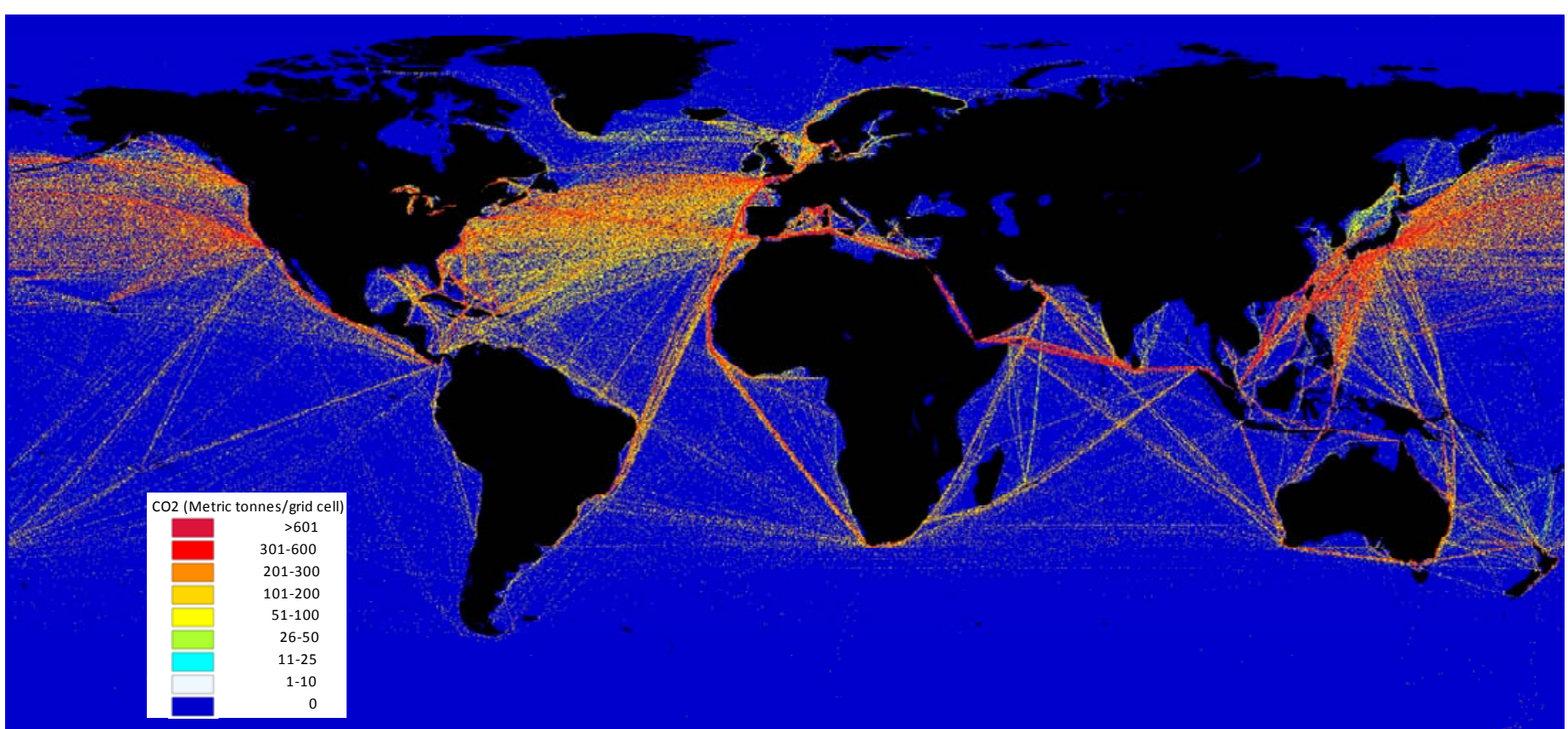

Source: data from (Wang C. J., 2007), cartography ITF, 
The geographic distribution of ship $\mathrm{CO} 2$ emissions matter little from a climate change perspective (this is not the case for other ship emissions such as NOx and SOx that have more localised impacts - see Box 1 ) but the geographic pattern of ship activity does have an impact as longer distance routing gives rise to greater emissions. Figure 4 illustrates gridded emissions of $\mathrm{CO} 2$ (expressed as metric tonne of carbon) in 2001 as extrapolated from detailed geo-referenced ship reporting schemes ${ }^{6}$. These account for a significant share of large commercial vessels in operation and illustrate the principal trading routes used by maritime transport.

\section{Relative Energy Efficiency and CO2 Emissions of Maritime Transport: Comparison with other} Modes

Maritime transport is characterised by large economies of scale in goods movement vessels are large, cargo capacity is voluminous and energy use or $\mathrm{CO} 2$ emissions per unit of transport work is relatively low. Assessing maritime transport energy or $\mathrm{CO} 2$ efficiency per tonne-kilometre, however, is not as straightforward as it might seem - beyond nominal load factors (accounting for laden vs. unladen containers), other aspects such as fleet heterogeneity, differences in duty cycles, on-ballast steaming and variable auxiliary power requirements all must be accounted for to provide an exact assessment.

For instance, trade imbalances and specific operating cycles for tankers result in average efficiencies that are less than these vessels' fully loaded efficiency (e.g. an oil tanker will run full to its destination port and will return with empty tanks under ballast - likewise, a container vessel operating eastbound in trans-pacific trade will have a higher loading of full containers than one operating westbound). Estimates of load factors for various vessel types range from $50 \%$ (tankers and bulkers, although the latter may experience higher average loadings of up to $60 \%$ due to triangular trading) to $70 \%$ for laden containers (e.g. excluding repositioned empty containers). Another factor to consider is vessel-specific power needs with some vessels requiring greater auxiliary power (e.g. for powering cargo climate-control systems) whilst others may require more powerful engines for higher speeds (container vessels).

Figure 5 indicates a range of relative $\mathrm{CO} 2$ intensities for freight transport for indicative purposes. Not all modes displayed below are interchangeable (e.g. bulk oil products not transported by sea are likely to be transported by pipeline rather than by road or rail and nonmaritime carriage of bulk dry goods will occur by rail rather than by road) and for intercontinental trade, maritime transport is the only available transport option. Nonetheless, some trade characteristics and transport distances are somewhat similar (coastal container vs. rail, intra-continental rail vs. large container vessel, Roll-on-Roll-off (RoRo) vs. truck and inter-continental container transport vs. air). Large container vessels compare extremely well with air (although the amount of overlapping cargo is limited to relatively high-value goods), whereas smaller container vessels' CO2 emissions per tonne kilometre are well within the range of rail but below truck transport. Roll-on, roll-off vessels have $\mathrm{CO} 2$ emission intensities in the upper range of diesel rail and in the lower range of road transport. 
Figure 5. CO2 Intensity of Selected Freight Transport Modes: Log Scale (g/tkm)

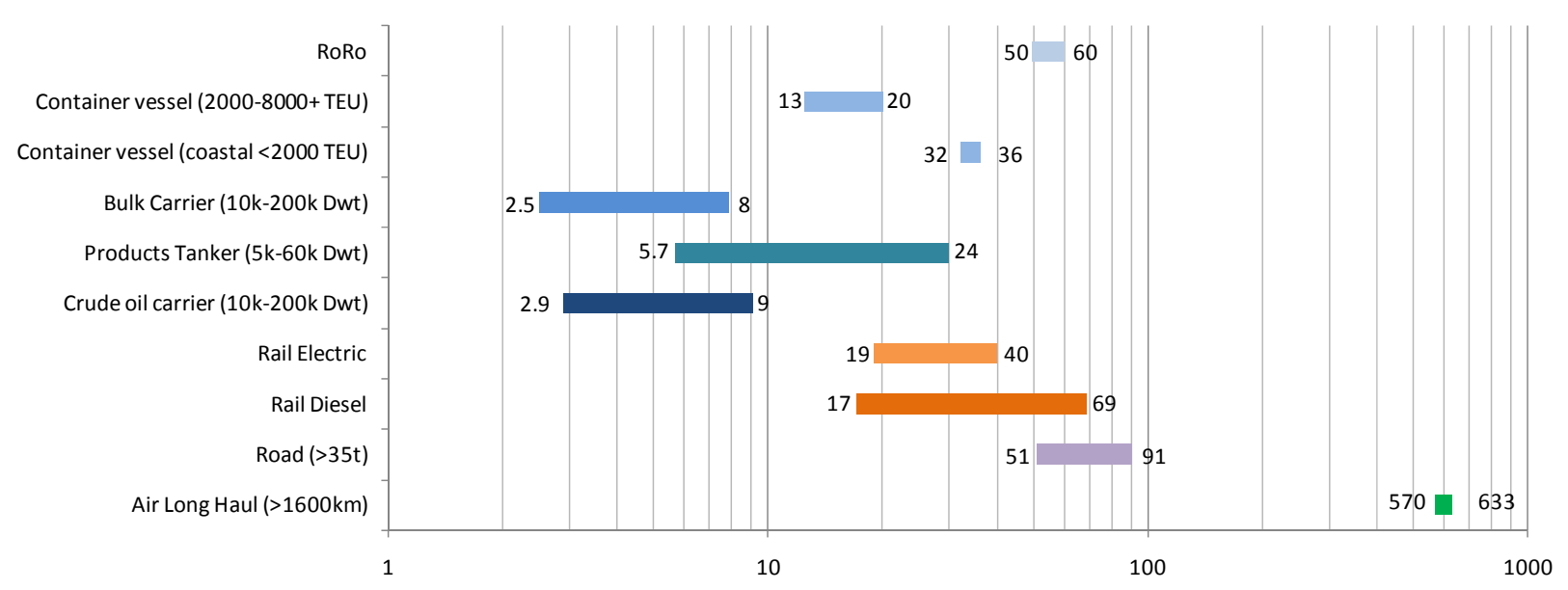

Source ITF estimates and (Buhaug, et al., 2008)

Projected Fossil Fuel Combustion and Greenhouse Gas Emissions from Shipping

The recent IMO study on greenhouse gas emissions from ships (Buhaug, $\varnothing$, et al, 2008) has sought to estimate future fuel use and CO2 emissions from shipping activity for 2020 and $2050^{7}$. It uses a model based on 3 driving variables (economic activity, transport efficiency and embodied fuel energy) which, in turn, are related to a number of secondary variables e.g. population, regional economic growth, oil prices, technical efficiency improvements, etc.). Macro-economic, energy use and demographic variables are drawn from the IPCC SRES family of scenarios and extrapolations of historic trends are adjusted ${ }^{8}$ according to specific factors that are likely to have an impact on maritime transport demand (expressed as tonne/miles). These factors include:

New gas pipelines from Myanmar to China (2030s)

New gas pipelines from the Middle East to India (2030s)

New gas pipelines from Russia to China (2010s)

Expansion of the North Africa-Europe Pipeline (2030s)

Modernisation of the Trans-Siberian Railroad (and diversion of container traffic thereupon, 2030s)

Opening of the Arctic Sea Route between East Asia and Europe ${ }^{9}$ (2040s)

Increase in scrap iron recycling equivalent to a $5 \%$ reduction in ore production

$7 \quad$ Another recent study by the Japanese Ocean Policy Research Foundation(Ocean Policy Research Foundation, 2008) has sought to estimate future levels of maritime activity and CO2 emissions. While the OPRF and the IMO studies are different in approach and in some of their findings, the (slightly) more recent IMO study has sought to incorporate the findings of the OPRF study and thus will be used as the main basis for discussing future maritime activity and emission trends. trends and another, based on the Japan Ocean Policy Research Foundation study that seeks to adjust the extrapolated trends to account for likely changes in the structure of maritime activity.

Due to the atmospheric warming-related retreat of the Arctic ice cap. 
These adjustments reduce maritime transport demand projections by up to half of what might otherwise been expected by extrapolating past GDP-maritime transport activity trends. The IMO study did not account for the impacts of the global economic recession although depressed economic activity in 2009-2010 will delay growth but is not expected to fundamentally change underlying patterns of growth (and thus maritime activity trends).

Buhaug, $\varnothing$, et al's central estimates for indexed future activity (indexed to 2007 tonne-miles) are set out in Table 2, below.

Table 2. Indexed Maritime Traffic Forecasts from IMO (tonne miles)

\begin{tabular}{|l|l|l|l|l|l|l|}
\hline & \multicolumn{7}{|l|}{ IPCC SRES Scenario (2007=100) } \\
\hline 2020 & A1B & A1F & A1T & A2 & B1 & B2 \\
\hline Ocean-going shipping & 131 & 131 & 131 & 121 & 120 & 114 \\
\hline Coastal shipping & 131 & 132 & 131 & 126 & 120 & 120 \\
\hline Container shipping & 194 & 193 & 195 & 176 & 173 & 165 \\
\hline Average all ships & 146 & 146 & 146 & 135 & 133 & 127 \\
\hline 2050 & A1B & A1F & A1T & A2 & B1 & B2 \\
\hline Ocean-going shipping & 245 & 245 & 245 & 190 & 185 & 155 \\
\hline Coastal shipping & 245 & 250 & 245 & 215 & 185 & 185 \\
\hline Container shipping & 900 & 875 & 905 & 645 & 615 & 525 \\
\hline Average all ships & 402 & 397 & 403 & 302 & 288 & 247 \\
\hline
\end{tabular}

Source: Source: Buhaug, $\varnothing$, et al, 2008

Overall tonne-miles are estimated to grow by $\sim 30-46 \%$ by 2020 and by $\sim 150-300 \%$ by 2050 . The IMO-commissioned study projects that container activity will grow by much more: $65-$ $95 \%$ by 2020 and $425-800 \%$ by 2050 . Growth in container movements has important GHG repercussions as the average installed power on container vessels is higher than on most other types of vessels due to higher speed requirements. Increased container vessel activity will result in greater maritime $\mathrm{CO} 2$ emissions than might otherwise have been expected based on past fleet structure.

The IMO projections assume increases in fuel efficiency stemming from changes in average ship size (where this makes commercial sense -- larger ships being more fuel efficient at constant load factors than smaller vessels), changes in speed (estimated vessel fuel consumption has been modelled based on a third power relationship between speed and engine power output) and technical improvements to new vessels. The IMO baseline projections assumes no increases in regulation of $\mathrm{CO} 2$ emissions or fuel consumption and so changes in efficiency (due to vessel design or operation) are assumed to track those improvements that are cost-effective under prevailing oil prices and commercial imperatives.

\subsection{Potential for Reduced Fuel Consumption and Efficiency Improvements}

In this section we review both technological and operational opportunities for further reducing energy use and GHG emissions from maritime activity. These are assessed on a first-order basis - that is by only looking at the potential percentage reduction in fuel use (or GHG emission, where appropriate) of each strategy. We do not discuss full cost assessment and marginal abatement costing, given incomplete data on technology costs as passed on by 
ship manufacturers or guarded operational cost data on the part of ship owners and managers ${ }^{10}$.

The technological options to reduce fuel consumption in ships can be broadly divided into five categories: Engine and transmission technology, auxiliary (non-propulsion) power systems, propulsion systems (including propellers) superstructure aerodynamics (especially for fast vessels) and hull shape. From an overall GHG emissions perspective, one might also consider alternative lower-carbon fuels and strategies that reduce VOC emissions and boiloff from tankers transporting volatile cargoes. Understanding the relative potential for each broad category requires some knowledge of basic principles of ship propulsion.

\subsection{Ship Propulsion Basics}

Fuel use by ships is directly linked to engine capacity and power output which, themselves are determined by vessel size and duty cycles. The latter, in turn, has a determining impact on vessel speed. Broadly speaking, fuel consumption increases as a third power function of speed as increased power output is required to move the mass of the vessel against hydrodynamic and aerodynamic resistance.

Ships must overcome three resistances in order to move forward:

frictional resistance (e.g. resistance generated by the interface between the hull and water), residual resistance (e.g. resistance generated by wave action on the hull and trailing eddy resistance behind the vessel), and

air resistance (e.g. conditioned by the aerodynamic characteristics of a vessel's superstructure).

Frictional and residual resistance are a function of the configuration of the vessel hull and of the amount of hull exposed below the waterline. Air resistance is a function of the surface exposed above the waterline and its form - vessels such as oil tankers will, when loaded, experience less air resistance than container vessels who by design have much more exposed superstructure and stacked cargo containers. The relative share of each of these resistance factors varies according to vessel speed (as well as size/displacement) as illustrated in Figure 6.

\section{Frictional Resistance}

Frictional or viscous resistance is the main resistance that must be overcome by slowermoving vessels and is a function of the area of the hull below-water ${ }^{11}$, its shape and its surface resistance characteristics. Frictional resistance increases at a rate more-or-lessequal to the square of the vessel's forward speed. For large bulk carriers and tankers, frictional resistance represents $70-80 \%$ of overall resistance declining to less than $40 \%$ for higher speed vessels such as container ships (MAN Marine, 2007). Hull fouling due to the surface accretion of barnacles, algae and sea plants can significantly increase this resistance

\footnotetext{
10 With the exception of the discussion of the marginal abatement cost of speed reduction since published reviews of this issue exist.

11 E.g. vessels under ballast will experience less frictional resistance than fully loaded vessels simply because they have less wetted hull.
} 
factor -- e.g. up to $40 \%{ }^{12}$. This resistance by fouling increases with ship operation (up to 25$50 \%$ over the lifetime of a vessel) and may require occasional hull cleaning and/or repainting. Propeller surfaces also degrade over time becoming rougher and requiring greater power output for constant speeds.

Figure 6. Total Ship Towing Resistance

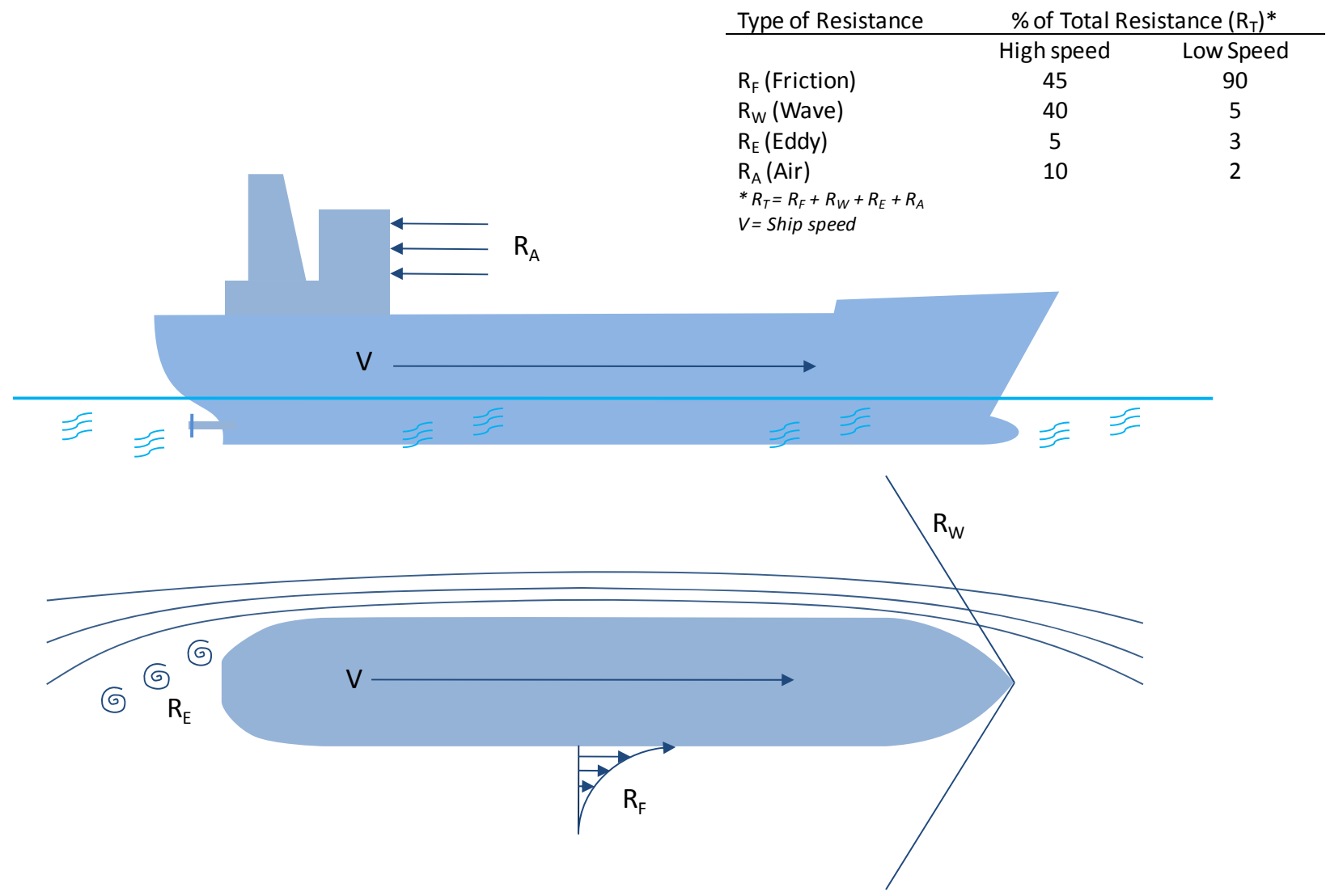

Source: adapted from (MAN Marine, 2007).

\section{Residual Resistance}

Residual resistance is a function of both wave resistance at the fore and eddy turbulence in the wake of the vessel. The kinetic energy of waves acts against the forward progress of the vessel just as flow separation at the aft of the vessel slows it down. Furthermore, a vessel moving through water creates its own kinetic trailing wave patterns that entail resistance. At slow speeds, wave resistance is proportional to the square of vessel speed but rises much faster at higher speeds. Adding more power for a given hull configuration results in diminishing speed gains up to a point where further power increases to the engine will not result in greater speed (e.g. the "wave wall"). Residual resistance represents as low as 8\% of overall resistance for low speed ships (nearly evenly distributed between wave and eddy constant speed or results in a $1 \%$ decrease in speed for a constant power output(MAN Marine, 2007). 
effects) while it can rise to as high as $60 \%$ of overall resistance for fast vessels - largely dominated by wave effects. Shallow water operation also leads to higher residual resistance.

\section{Air resistance}

In calm conditions, air resistance is proportional to the square of vessel speed and a function of the cross-sectional area of the vessel facing the wind (or facing the direction of travel). At $2 \%$ of overall resistance at slow speed, air resistance is a relatively minor factor when compared to other sources of resistance but this can rise up top 10\% of fast moving vessels with large exposed cross-sections.

The sum of these three resistance factors for a specified duty-cycle speed, determines the effective minimum power output of the vessel's main engines. However, rough weather conditions can increase resistance by as high as a factor of .5 to 1 (and up to 2 in some instances). Accounting for an appropriate "sea margin" must be made in accordance with the expected trading patterns for new vessel builds. A second factor to consider in determining engine size and power output is the propulsion efficiency and configuration of the propeller(s).

\section{Propeller Efficiency}

Just as the vessel hull experiences frictional and residual resistance, so too do the blades of the propeller or propellers. The phenomena of increasing surface resistance, detached flow and eddy effects are amplified by the fact that the typical aft position of the propellers means that they themselves are operating in a turbulent wake field. The resistance that propeller blades must overcome is exacerbated by the speed of rotation and turbulent boundary flows between the hull, the rudder and the propeller blades. Because of this, there is a non-linear and decreasing relationship with the amount of power supplied to the propeller shaft, the resultant propeller thrust and ultimate vessel speed. Reduced propeller speed for a constant power input due to the culmination of resistance factors is known as "heavy" propeller condition. Important design factors that reduce heavy propeller running include propeller blade size and pitch, rate of advance through the water, rate of rotation and the number of blades $^{13}$. Propeller shaft efficiency is also important to address through strategies to reduce shaft friction.

\section{Marine Engines}

Most ocean-going cargo vessels are powered by extremely large slow-speed two-stroke engines that are directly coupled to the propeller shaft (e.g. they have no clutch or reduction gears). Two-stroke marine engines have high power outputs (up to nearly $85 \mathrm{~mW}$ ), are relatively efficient (approximately $50 \%$ of the fuel energy is delivered directly to the propeller shaft $^{14}$-- see figure 7) and are adapted to burning heavy fuel oil via direct injection. The combined elevated power output and slow engine speed (ranging from 60 to $200 \mathrm{rpm}$ ) is suited for most ocean-going cargo applications. Some very large cargo carriers and most passenger ships and ferries require more acceleration power and are built with mediumspeed 4-stroke NDO or HFO engines. The combination of high-temperature combustion and

\footnotetext{
13 Additional contributory factors to heavy propeller running include ship size (Small ships are more prone to heavy propeller running because wave action has a relatively larger impact than on larger vessel hulls), vessel speed (since waves will act on the hull with more force), and hull form (a flat stem is more prone to being slowed by wave action than a v-shaped stem). relatively slow bulk vessel). (Stopford, 2009).
} 
low quality fuels leads to very high rates of NOx and SOx emissions when compared to current land-based diesel engines that have already gone through several pollution reduction design cycles.

\section{Figure 7. Marine 2-Stroke Engine Efficiency}

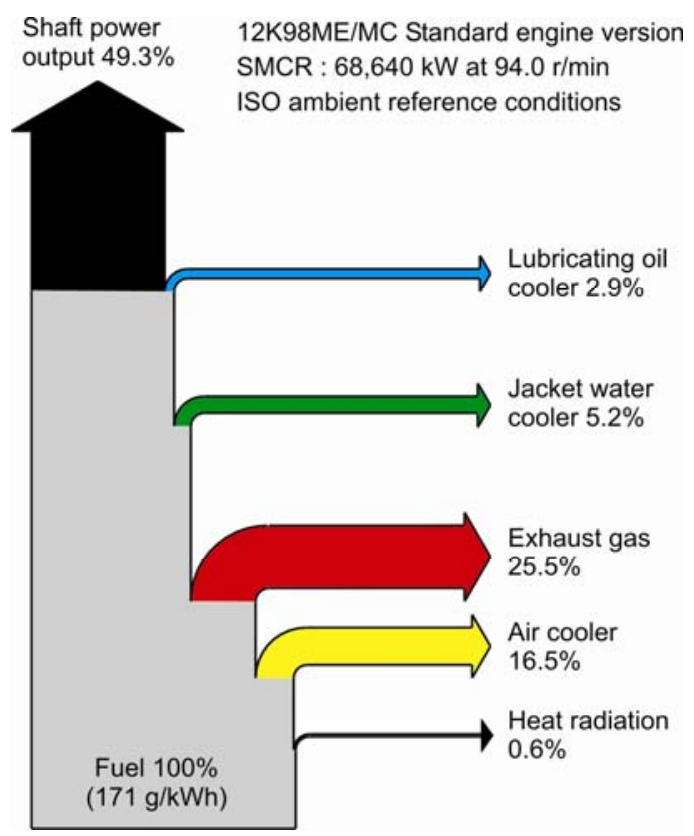

Source: Man B\&W 19/07/2005, Thermo Efficiency System

\section{Vessel Duty Cycles}

Ocean-going vessels are designed for very different duty cycles which have an incidence on engine power requirements, auxiliary power needs and, thus, on fuel consumption and $\mathrm{CO} 2$ emissions. Vessel duty cycles also have an incidence on operational factors (such as routing and port time) that also are linked to fuel use and CO2 emissions. Vessel speed is key for some applications (e.g., containers), auxiliary power requirements are important for others (refrigerated cargoes). Some duty cycles are characterised by multiple short stops (RoRos, ferries), others by long outbound trips with ballast-only returns (e.g. oil and many other tankers). Some vessels' cargoes can change ownership en route leading to trip diversion and sub-optimal routing (e.g. bulkers) while others are subject to time constraints that may require navigating in heavy weather conditions. Finally, some vessels may be configured to trade in specific conditions (e.g. ice class vessels). These and yet other duty-cycle related factors linked to the commercial nature of international maritime shipping ultimately have an important impact on $\mathrm{CO} 2$ emissions and must be considered when evaluating specific GHG mitigation options.

\subsection{Review of Technology and Operational Fuel Saving Strategies}

In this section, we examine various fuel saving and $\mathrm{CO} 2$ emission reducing strategies for the maritime transport sector ${ }^{15}$. These are broadly grouped into strategies impacting vessel design, engine design, propulsion systems, other technology-related strategies and operational measures. The focus is on existing measures that can be implemented relatively 
quickly and an indication is given as to the measure's payback period (as a range from short=1-3 years to long=more than 15 years). No detailed cost estimates are given, nor are marginal abatement costs provided as these could not be assessed due to lack of data ${ }^{16}$. Not all strategies make sense for all vessels and so an indication is given as to which class of vessels are most likely to benefit from each individual strategy. The strategies are characterised as to whether they must be incorporated into the vessel design process and thus are only applicable for newbuilds or whether they can be applied to existing vessels either through technology retro-fits or because they are operational measures. Finally, the upper bound of the overall ship-wide fuel savings and $\mathrm{CO} 2$ reduction impact are provided as a percentage reduction from a vessel not implementing the strategy in question.

\subsubsection{Overall vessel design}

Overall design strategies that impact the size of the vessel, its displacement, its dimensions, its handling characteristics under loaded and ballast conditions and its hull configuration all have an impact on fuel use and CO2 emissions for specific duty cycles. These are summarised below along with the potential fuel consumption reduction averaged across various uses and vessels.

16 Though marginal abatement costs of speed reduction will be discussed later in this section. 


\section{Strategy}

Tanker/bulker

- Container

Ro-ro

Ferry-Cruise

Offshore

supply

Efficiency of Scale

000

Design for reduced ballast operation

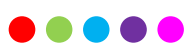

Lightweight Construction

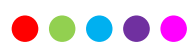

Optimum hull dimensions
Description

Larger vessels will have a relatively better efficiency

per unit of work accomplished (e.g. in terms of energy expended per tonne-kilometre). Regression

analysis of recent newbuilds indicates that an increase in vessel size of $10 \%$ will result in $\sim 4 \%$ greater specific efficiency. Short payback.

Designing a vessel to operate with less ballast can represent an important efficiency gain. Lighter displacement means lower wetted hull surface and results in lower resistance. Ballast must be sufficient to preserve stability, handling (e.g. to avoid hull slamming) and immersion of the propeller at optimum depth ${ }^{17}$. Short payback.

Replacement of steel by lighter weight alternatives in non-structural elements can lead to fuel efficiency gains. Replacing steel with lower weight high tensile steel can also reduce fuel consumption. Both of these strategies come with relatively significant cost and care must be taken to balance direct $\mathrm{CO} 2$ reductions linked to reduced fuel consumption to the higher $\mathrm{CO} 2$ intensity of mining and smelting lighter weight alternatives. For indicative purposes; a $20 \%$ reduction of steel weight will result in approximately $9 \%$ lower power requirements for a given vessel configuration and service speed. Short payback.

Optimising hull length and fullness for reduced frictional resistance can have a significant impact on fuel consumption. Too large a length to breadth ratio increases wetted surface and frictional resistance while too large a breadth to length ratio leads to increased residual resistance. Designing a typical product tanker to be $10-15 \%$ longer can reduce engine demand by $\sim 10 \%$ for a constant speed. However, this is an expensive option as $<9 \%$

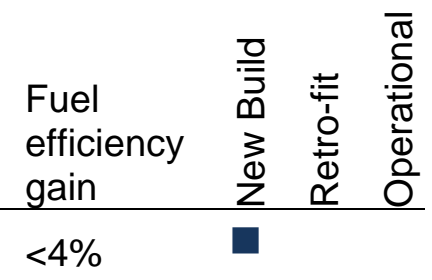


increased length increases vessel newbuild costs. Long payback.

Low-profile hull openings

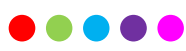

Interceptor trim plates

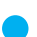

\begin{abstract}
Aft waterline extension
\end{abstract}

Shaft line alignment

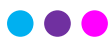

Skeg shape trailing edge

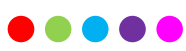

Air lubrification

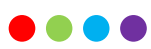

Bulbous bow
Turbulence from interrupted water flow at hull openings (e.g. bow thrusters tunnels, sea chest openings, etc. can increase resistance and fuel consumption. Scalloping these or otherwise designing these openings to reduce flow disturbance can improve fuel efficiency. Short payback.

A vertical underwater extension at the rear of the hull that channels the high pressure flow behind the propellers downward thus creating a lift effect. An option suitable for relatively high speed vessels such as RoRos and Ferries. Short payback.

A tapered aft extension of the vessel at the waterline that both extends the effective waterline and reduces the trailing separation flow turbulence. Can be combined with an interceptor plate for better results. Short payback.

Aligning propeller shafts to minimise turbulent flow and frictional resistance can reduce overall power demand and ensuing energy consumption. Short payback.

The skeg is an extension of the hull leading up to the propeller shaft line and disc. Optimising the form of the skeg to deliver low-speed but still-attached (non-turbulent) flows to the propeller disc can reduce engine power output requirements. Short payback.

A recess formed over the length of a vessel's hull into which compressed air can be pumped effectively reduces frictional resistance by "lubrifying" the hull-water contact area. Despite requiring some auxiliary pumping power, this design strategy can reduce fuel use by up to $15 \%$ for largesurfaced hulls on slower-speed vessels (e.g. tankers). Fuel savings for container vessels and car carriers are about half as much. Medium payback.

A bulbous bellow-the-waterline extension of the bow $<20 \%$ can improve water flow around the hull and reduce drag for large vessels operating within commercial speed ranges. $<4 \%$ $<7 \%$ $<2 \%$

$<5 \%$

$<2 \%$

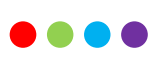




\section{Engine design}

Engine design, size and power output determine fuel use and emissions - as such, it is during the vessel design phase that the greatest changes can be made to reduce fuel consumption by specifying the most efficient engine adapted to the vessel's size and intended duty cycle. At present, there are no mandatory fuel economy standards for maritime engines though there are mandatory rules and standards relating to NOx emissions under MARPOL. Given that there is an inverse relationship between NOx emissions and engine fuel consumption (and thus CO2, emissions), international efforts to further reduce NOx emissions from shipping will likely entail an increase in CO2 emissions (although the specific increase in fuel consumption depends largely on the NOx control strategy implemented).

\begin{tabular}{ll}
$\begin{array}{l}\text { Strategy } \\
\text { Tanker/bulker } \\
\text { Container } \\
\text { ORo-ro } \\
\text { Ferry-Cruise } \\
\text { Offshore } \\
\text { supply }\end{array}$ & \\
\hline Engine derating & $\begin{array}{l}\text { Marine engine designers can tune engine } \\
\text { performance according to an engine's specific } \\
\text { power-speed layout map and propeller shaft torque } \\
\text { requirements. Adding an additional cylinder and } \\
\text { permanently operating the engine at a lower point } \\
\text { on the resultant engine-speed map ("de-rating") can } \\
\text { reduce fuel consumption for a constant vessel } \\
\text { speed. Medium payback (Wettstein \& Brown, 2008). }\end{array}$
\end{tabular}

Diesel electric drives

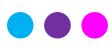

Combined diesel-electric and dieselmechanical drives

Waste heat recovery
Substituting coupled electric drives for the $5-30 \%$ traditional direct engine-propeller shaft connection can deliver substantial savings, especially where frequent changes in shaft load and operating profiles are required (e.g. with frequent manoeuvring). Medium payback.

Combining electric drives for part-load operation and fully coupled mechanical drivetrains for full load operation can optimise engine performance for vessels with variable engine load requirements. Long payback.

Capturing and re-converting engine exhaust gas heat into electric energy can reduce direct engine fuel requirements for electric-coupled propulsion systems or reduce auxiliary engine requirements. Recovered heat can also be used for other shipboard functions (e.g. fuel heating). Medium payback. 
Enhanced engine tuning and part-load operation

Common rail engine
Tuning engines to operate most efficiently in the most commonly used load ranges can reduce overall fuel use despite a greater fuel use penalty for seldom-used full load operation. Engine load matching based on more common part-load operation requires a different engine mapping and may entail changes in cam profiles and injection timing. Short payback.

Common rail marine engines exhibit the same benefits as automotive common rail technologies in that combustion can be optimised over the entire engine operating field. Short payback.
$<4 \%$

$<1 \%$ 
Propulsion systems

Strategy

Tanker/bulker

Container

oRo-ro

Ferry-Cruise

Offshore

supply

\section{Description}

Fuel

gain

Wing thrusters

shaft main propeller results in fuel savings

$<10 \%$

compared to a twin-shaft design. Energy savings

stem principally from reduced friction from the

smaller thrusters pods. Medium payback.

Counter-rotating

propellers

Coupled counter-rotating propellers allow for the

trailing aft propeller to recover some of the energy

from the slipstream of the forward propeller.

Optimised

Optimised design of the hull, protruding

$<4 \%$

propeller-hull

interface

appendages and the propeller(s) to reduce frictional

and residual resistance results in reduced hull-

propulsion system interference and improved fuel consumption. Short payback.

Propeller-rudder

Unit

Rudder drag accounts for up to $5 \%$ of ship

resistance. Optimised rudder design and

coordinated rudder-propeller shape (e.g. with a

rudder bulb) will reduce this drag and save fuel.

Medium payback.

Optimised

Propeller blades designed for reduced friction and

$<2 \%$

propeller blade cavitation reduce fuel consumption. Short payback.

sections

Propeller tip

Winglets

Propeller nozzle
Just as winglets reduce trailing turbulence on aircraft wings, so too do propeller tip winglets for ships.

A propeller nozzle is a wing-section shaped ring circling the propeller which reduces trailing turbulence up to speeds of 20 knots.
$<4 \%$

$<5 \%$ 
Propeller

Efficiency

Monitoring

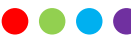

Efficient

Propeller Speed

Modulation

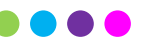

Pulling Thruster

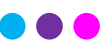

Wind power:

Flettner rotor

Power:

Kites and Sails
Monitoring propeller operational efficiency variables

such as speed, torque and thrust and modifying

engine output accordingly can enable operational

fuel savings. Short payback.

Operating controllable-pitch propellers at constant rpm over a wide range of ship speeds is inefficient. Reducing propeller rpm to match ship speed without rather than modulating propeller pitch can deliver fuel savings.

Combining thrusters with a pulling propeller (e.g. a forward-facing propeller) in either a counter-rotating centre-line setup or as wing thrusters can reduce fuel use for vessels requiring frequent operation at variable loads.

A Flettner rotor is a spinning vertical rotor that converts wind power into propulsive energy. This set-up harnesses wind power irrespective of its direction and can considerably reduce fossil fuel use although performance is linked to wind speed and strength. However, it requires free deck space for rotor placement. Long payback.

Traditional sail configurations with advanced fabric or composite materials and/or kites attached to the bow can harness wind power for forward propulsion. Sails and kites can greatly reduce primary power requirements but can experience variable performance depending on wind speed and direction (kites, however, can better exploit constant speed winds at altitude). Sails also require available deck space. Long payback. $<30 \%$

$<4 \%$

$<5 \%$

$<10 \%$

$<20 \%$ 
Other technology strategies

Strategy

Tanker/bulker

Container

Ro-ro

Ferry-Cruise

Offshore

supply

Description

\begin{tabular}{|c|c|c|}
\hline $\begin{array}{l}\text { uel } \\
\text { fficiency } \\
\text { ain }\end{array}$ & 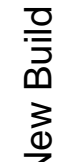 & 芦 \\
\hline
\end{tabular}

Low-loss electric drive

Consolidating power transformation and reducing

$<2 \%$ the number of transformers for electric drives reduces distributional losses. Especially useful for vessels whose duty cycles require extensive partload operation. Medium payback.

Hybrid auxiliary power Hybridising auxiliary power generation to operate at

$<2 \%$ generation steady optimal load can deliver important auxiliary engine fuel consumption reductions. Other benefits of hybridised engines coupled with battery storage include sourcing non-fossil sources of energy such as wind or solar power. Short payback.

Variable speed electric power generation

Generating shipboard power via variable rpm generating sets (as opposed to shaft-linked single speed generating sets) can better align specific generating capacity with onboard power needs. Medium payback.

Energy saving More efficient lighting (and heating) can reduce lighting auxiliary power needs.

Enhanced power management

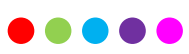

Solar power

Variable speed pumps

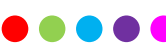

Managing onboard power requirements efficiently so as to optimise the number of active electric power generating sets and minimise the extent of multiple generator low-load operation can lead to significant overall fuel savings. Medium payback.

Generating electricity and heat via on-deck solar panels reduces fuel consumption related to auxiliary power and heating requirements. Medium payback.

Engine cooling pumps circulate large fixed amounts of water through engine cooling circuits irrespective of engine power output and cooling requirements. Operating variable speed pumps that best match cooling water flow to engine cooling needs can save energy.
$<5 \%$

$<4 \%$

$<1 \%$ 

systems that optimise vessel performance across relevant vessel sub-systems (engine, propeller, ballast, etc...) for minimal fuel consumption can deliver substantial fuel savings. Short payback. 
Operational strategies

Strategy

Tanker/bulker

Container

Ro-ro

Ferry-Cruise

Offshore

supply

Description

efficiency

gain

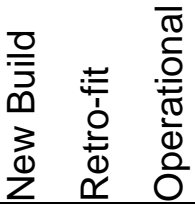

Fuel additives

Fuel additives that reduce soot build-up in exhaust

$<2 \%$ systems can have a positive impact on fuel efficiency. Medium payback.

Port turn-around

Faster port turn-around times allows for slower

$<10 \%$

time

speeds at sea (port congestion allowing) for vessels operating on fixed schedules. Design features such as ramps and hold access alongside with port-side improvements (e.g. efficient gantry cranes) can make speed reduction at sea a commercially attractive option. Short payback.

Propeller surface maintenance

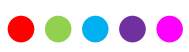

Hull coating

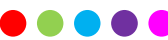

Hull cleaning

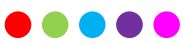

Ship speed reduction

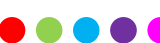

Wet cleaning and polishing propeller surfaces to reduce roughness and the accretion of organic materials can significantly reduce propeller resistance and improve fuel efficiency. This can be accomplished without removing the vessel from its commercial duties.

Hardened low-resistance hull coatings reduce $<5 \%$ frictional resistance and can, with certain additives, reduce fouling by aquatic organisms. The compound impact is a lasting reduction of hull friction which is the principal source of friction in vessels. Short payback.

Organic growth on the vessel hull can be a significant source of drag. Frequent hull cleaning can lead to improves fuel consumption. Short payback.

Reducing ship speed is one of the most effective $<23 \%$ ways of reducing fuel use and $\mathrm{CO} 2$ emissions.

Engine power output requirements is more-or-less a cubic function of ship speed thus small reductions in speed can deliver important reductions in fuel consumption - e.g. a 1,2 and 3 knot reduction in ship speed results in 11\%, $17 \%$ and $23 \%$ reductions in energy consumption respectively. Ship speed reductions, however, are subject to duty cycle constraints. Short payback. 
Voyage planning and weather routing

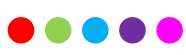

Optimised vessel trim

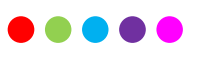

Optimised

autopilot

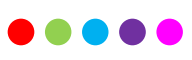

Overall energy awareness

Condition-based maintenance

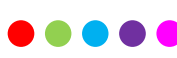

Optimal berthing, mooring and anchoring
Due to prevailing currents, wave heights, winds and weather patterns, the shortest distance between two points is not necessarily the fastest or the most fuel efficient. Modern weather and sea condition monitoring systems combined with navigational computers allow for fuel efficient routing based on real-time weather and sea conditions and can contribute to important fuel savings. Short payback.

Optimised vessel trim for given draught and speeds $\quad<5 \%$ can enhance fuel efficiency. Trim should be optimised by appropriate cargo positioning or bunker distribution as taking on additional ballast will increase displacement and result in higher. fuel consumption

Automatic ship course-keeping requires more-orless frequent changes in rudder position to account for wind, currents and ship yawing. Advanced adaptive autopilot systems can reduce overall course changes and thus reduce overall travel distance and corresponding fuel use.

Creating a company-wide internal set of incentives $\quad<10 \%$ for fuel-efficient operations can ensure that fuel efficiency considerations are integrated into daily vessel operations. This approach requires a close link between crew management responsibilities and the parties responsible for fuel costs - this is oftentimes not the case in the maritime sector.

Ensuring that hull, propulsion and engine systems are all maintained at high levels of fuel efficiency performance can be greatly facilitated by real-time monitoring of sub-system performance conditionbased, rather than schedule-based, maintenance.

$<10 \%$

$<5 \%$

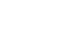

d

\author{
(2)
}

$<5 \%$

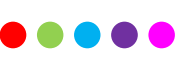

\subsection{Overall Fuel Efficiency Potential from Technical and Operational Strategies}

The specific energy efficiency gains detailed above are not additive but based on these potentials, overall potential $\mathrm{CO} 2$ emission reductions from current vessel design strategies for newbuilds can be estimated to be in the range of 5-30\%. Technical retrofit and maintenance strategies can potentially reduce $\mathrm{CO} 2$ emissions from the existing fleet by 4$20 \%$ while operational strategies might potentially reduce fuel use and CO2 emissions by as much as 40\% (Hobson, et al., 2007). Combined technical and operational measures have been estimated to potentially reduce $\mathrm{CO} 2$ emissions by up to $43 \%$ per tonne-kilometre by 2020 and by up to $63 \%$ per tonne kilometre by 2050 (Berrefjord, et al., 2008). 
However, these potentials fuel savings remain just that - potentials. Experience has shown that while potential fuel savings may be important, the reality is that ships are designed and operating according to many criteria - of which fuel savings (and $\mathrm{CO} 2$ emissions by proxy) are but one. Box 2 describes how factors such as market reactivity, capital constraints, duty cycles and environmental awareness act on the uptake of fuel efficiency technologies and

\section{Box 2. Factors Influencing the Uptake of Fuel Efficiency measures for Commercial Shipping}

The extent to which technological improvements are being implemented within the world fleet varies from sector to sector and within that from company to company. The arguments for and against the implementation of a particular design are generally complex and interlinked. The following is a list of factors that may influence a company's decision regarding the design of a new vessel:

- Short lead time on new vessels to enter the marketplace quickly.

Should there be a shift in the market, for example a steep rise in the demand for oil, then new vessels would need to be built to deal with this increased trade. The quicker you get to the market the more trade you can secure and the quicker the return on your investment. Hence time spent on design refinements may be viewed as a waste of time. The operating cost may not be a priority as the available freight rates could more than compensate for any reduced efficiencies.

- Sensitivity to capital expenditure.

A company may simply not have the finances available at the time to build their ideal vessel. In an attempt to reduce capital costs, technical refinements, which may reduce subsequent running costs over the life of the vessel may not be investigated and implemented.

- Route-specific vessels

If a vessel is to be designed for a particular route on which it will operate for the majority, if not all, of its lifetime, then the task of optimising for operating efficiency becomes a priority. Being near certain of its mission profile at the design stage makes the process of optimisation easier as certain constraints and restrictions can be excluded. For example no draft restrictions may allow an optimal hull to be designed.

- Cargo type / speed of operation.

The design speed of a vessel and the type of cargo it carries are very closely linked. Ships carrying high value cargo (such as finished manufactured goods) or people, demand high speed vessels (circa 25 knots) where as unfinished, lower value cargo such as crude oil, coal and ore can be transported at slower speeds (circa 16 knots). With ships the relationship between speed and power is a cubic one, so to increase the speed of a vessel by a factor of 2 (e.g. from 12 to 24 knots) the power would need to be increased by a factor of 23 or 8 times (e.g. from $10 \mathrm{MW}$ to $80 \mathrm{MW}$ ). Therefore the higher the speed the more attention needs to be given to operational cost, in particular fuel costs. Container vessels tend to operate in the 25 knots range and hence operators of these types of ships generally tend to be interested in technical developments aimed at reducing fuel consumption. Companies implementing technological developments in vessel design include, for example, Hapag-Lloyd and Maersk Line, both predominately operating container vessels.

- Environmental awareness.

Some operators now implement design and operational changes in an effort to reduce the impact that their operations have on the environment. Maersk Line is a good example of this type of practice. They have implemented waste heat recovery systems on all their vessels built in a particular ship yard, common rail engine technology for all newbuilds and a program of replacement of older auxiliary and cargo handling engines to reduce their exhaust emissions.

Source: excerpt from (Hobson, et al., 2007) 
operational practices

An additional factor to consider in the uptake of vessel fuel efficiency technologies is the relationship between the vessel owner responsible for the design specification of the hull, propulsion and engine technologies and the party that is ultimately responsible for fuel costs. Many maritime trades are characterised by a principal agent problem where these two are not the same. Ships, especially bulk carriers and some tank and container vessels are often hired under one or several successive charter party agreements (in some cases, more than 10). Vessel charter party contracts can be for the vessel alone, for the vessel and crew, for the vessel, crew and cargo, or for various permutations of the preceding arrangements. Depending on the particular charter party contract, fuel costs may be borne by the owner, the vessel operator or the cargo owner. Further complicating the matter is that ownership of the cargo (and responsibility for fuel costs) may change whilst the vessel is already underway. While fuel costs represent an important running cost and ship owners are therefore under pressure to specify ship technologies for their newbuilds that are competitive under prevailing market conditions and expected energy prices, the reality is that the lack of direct responsibility for ship fuel costs and the pressure of other commercial criteria mean that many newbuilds are characterised by less-than-full potential fuel economy. This is much less the case when vessels are built and designed for owner-operators.

A similar principal agent problem also exists for realising the full potential for operational fuel savings and $\mathrm{CO} 2$ reductions in that responsibility for en-route fuel consumption may be diluted amongst several distinct parties - the vessel owner, the vessel operator and crew manager and the cargo owner.

Despite these challenges, vessel owners and operators have been responsive to energy prices and have sought ways to improve to some extent the overall energy efficiency of newbuilds and reduce the energy consumption of existing vessels through operational changes and technology retrofits. It is the latter two categories - operational adjustments and retro-fits - that have represented the first response to increased energy costs. Of these, speed reduction is one of the most effective adjustments that vessel operators can make to rapidly reduce energy consumption.

Already in the early 1970's, the maritime sector responded to rapidly increasing oil prices by first instilling "slow steaming" and only then by exploiting economies of scale through the specification larger and larger vessels - some of which rapidly became uneconomic under lower oil prices. The rapid spike in oil prices in the first half of 2008 also saw many vessel operators return to speed reductions, especially for relatively high speed container services. In some cases, fuel savings from reduced speed travel more than offset the costs of adding an additional vessel on certain routes in order to maintain schedule frequency and capacity ${ }^{18}$. Because the engine power requirements (and hence fuel consumption and $\mathrm{CO} 2$ emissions) are a cubic function of speed, relatively small reductions in speed - especially from relatively elevated speeds - can deliver significant fuel savings (see table 3).

${ }^{18}$ (Corbett, Wang, \& Winebrake, 2009) 
Table 3. Impact of Speed Reduction on Vessel Fuel Consumption (8500 TEU Container vessel)

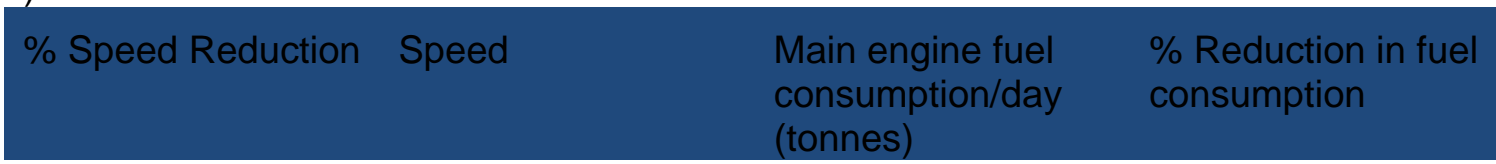

\begin{tabular}{|cccc}
\hline 0 & 25 & 230 & \\
$10 \%$ & 22.5 & 168 & $27 \%$ \\
$20 \%$ & 20.0 & 118 & $49 \%$ \\
$30 \%$ & 17.5 & 79 & $66 \%$ \\
$40 \%$ & 15.0 & 50 & $78 \%$ \\
$50 \%$ & 12.5 & 29 & $87 \%$ \\
\hline
\end{tabular}

Source: Own calculation from data in (Corbett, Wang, \& Winebrake, 2009) and (Stopford, 2009) 


\section{Box 3. Costs and Marginal $\mathrm{CO} 2$ Abatement Cost of Speed Reduction for Container Vessels}

Liner services are optimized to provide fixed and dependable service schedules to shippers on the basis of commercial and market concerns. Because container vessels are fast, speed reductions are an easy way of reducing vessel fuel consumption with relatively little effort. However, when speed reductions impact service frequency and quality, liner operators face added costs (or lose competitive position). Further, speed reduction reduces fuel costs but will increase other fixed daily costs to the liner operator since voyages are take more time. All of these potential impacts must be considered when the operator contemplates reducing speed to save money.

The table below, based on a simple container service cost model, explores the cost impacts of speed reduction in the face of increased fuel costs when an operator wishes to maintain service quality on a route (e.g. port call frequency). In the case of a string of 8500 TEU vessels serving 7 ports weekly over a voyage distance of 14000 nautical miles, an increase in bunker fuel costs from $\$ 300$ to $\$ 550$ per tonne leads to added yearly fuel costs of $\$ 66$ million. An operater reducing speed by $\sim 20 \%$ and adding an extra vessel in the service string would potentially save $\$ 31$ million despite added ship-related costs. This simplified model confirms observed behavior among major liner service providers during the fuel price spike experienced during the summer of 2008.

Comparison of yearly container service costs

8500 TEU vessels, 14000 mile service schedule, weekly frequency, 7 port calls per voyage

Baseline

5 ships, \$300 tonne/Fuel

Speed (knots)

Total Service Costs

(million \$ per yr)

Total Bunker costs

(million \$ per yr)

Voyage duration (days)

Voyages per year

Required number of

ships for service string

Bunker price

80
38.1 9.6

300
Normal Speed

5 ships, $\$ 550$ tonne/Fuel
Slow speed 6 ships, \$550 tonne/Fuel 248

147 104 38.1 44.5 9.6

550

Source: calculations based on (Stopford, 2009), excludes terminal, inland handling and container costs

Corbett, Weng and Winebrake (Corbett, Wang, \& Winebrake, 2009) look at the potential aggregate impacts of speed reduction for liner shipping to and from the United States. They look at potential fuel savings and CO2 emission reductions under two scenarios; one where vessels slow down and service frequency falls and another where vessels slow down and ships are added to retain service frequency. They find that fuel-related $\mathrm{CO} 2$ reduction in the first scenario (reduced frequency) is about twice that of the second scenario (maintained frequenced by adding vessels). On the basis of this earlier work, Wang (Wang H. , 2009) calculates a first-order* marginal abatement cost curve for speed reduction by looking at the deviation from economically optimal containership speeds. He finds that at a fuel price of $\$ 300 /$ tonne, a $10 \%$ reduction in speed results in a marginal CO2 abatement cost of $\sim 20 /$ tonne and a $25 \%$ reduction in speed has a marginal abatement cost of $\$ 50 /$ tonne.

These cost estimates are relatively low but indicate that speed reduction is not a "free" CO2 abatement measure for shipping. However, operators may be working from different baseline cost assumptions as several have not only instilled slower service speeds but have estimated that even at fuel costs in the range of $\$ 250-\$ 350 /$ tonne, slower speed service schedules makes economic sense - especially as sea trials have indicated few adverse effects from sub-specification part-load functioning of vessel engines**.

*e.g. excluding the costs of adding additional vessels to a service string to maintain frequency

**personal communication from Maersk 
Clearly, operators have used speed reduction as a response to high fuel costs but there are few public assessments of what speed reduction "costs" operators and what the potential marginal cost of reducing $\mathrm{CO} 2$ emissions via speed reduction might be. Preliminary evidence (see Box 3 ) indicates that speed reduction is not "free" and that the marginal abatement costs may be in the order of $\$ 20-\$ 50$ per tonne of $\mathrm{CO} 2$ (for a speed reduction in the order of $10 \%-25 \%$ and a fuel price of $\$ 300 /$ tonne, though real costs faced by commercial operators may be lower ${ }^{19}$.

Optimum vessel speeds from the perspective of fuel consumption are not necessarily the slowest speeds when all factors are considered (see below) however, there is evidence that there is a real gap between optimum travel speeds and actual speeds. One small survey revealed that real fuel consumption can be as high as $26 \%$ over "optimum" fuel consumption - largely due to differences in travel speed. Close monitoring of optimum versus real fuel consumption and adjusting travel speed accordingly (among other factors) can reduce this gap to around $4 \%$ with most of the remaining gap due to port-side cargo operations and delays (Bond, 2008).

Even in the case of seemingly straightforward fuel saving options such as speed reduction, several commercial or operational imperatives may prove more important than reducing fuel costs and $\mathrm{CO} 2$ emissions. The first is that the value of the cargo determines the relative share of fuel vs. time costs for the voyage in question. Vessels carrying high value cargoes with time-sensitive delivery will be less likely to reduce speed even under increased fuel prices. A second factor to consider is overall vessel or service (in the case of container routes) costs including all operating and port costs. For example, slower steaming may entail night-time or week-end port arrivals when container handling costs may in some ports be much higher than during regular port hours. Port congestion may also play a role in that its avoidance may either entail faster or slower steaming. Finally, many vessel operators hedge their fuel costs by purchasing advance contracts on fuel oil. Hedging may buffer the impact of short price spikes (and reduce pressure to save fuel), or, conversely, prolong the impact of high oil price spikes (for operators taking contracts at or near peak prices) and thus increase the pressure on operators to reduce speed and otherwise save fuel.

A final factor to consider in the extent with which potential fuel economy gains are realised is the rate of turn-over in the world fleet. Ships represent a considerable capital investment and, like aircraft, have relatively long commercial lives. As of 2006, the average age of vessels being withdrawn from commercial service for recycling had risen to approximately 32 years up from approximately 27 years in the early 1990s (see Figure 7). Long vessel life means that only a small share of the overall fleet will have been replaced by 2020 - this means that operational and maintenance-related efficiency gains will likely dominate over the short- to medium-term with new vessel and propulsion technology-related gains slowly becoming more important out to the 2050 horizon. 
Figure 7. Average Age and Gross Tonnage of Vessels withdrawn from Commercial Service

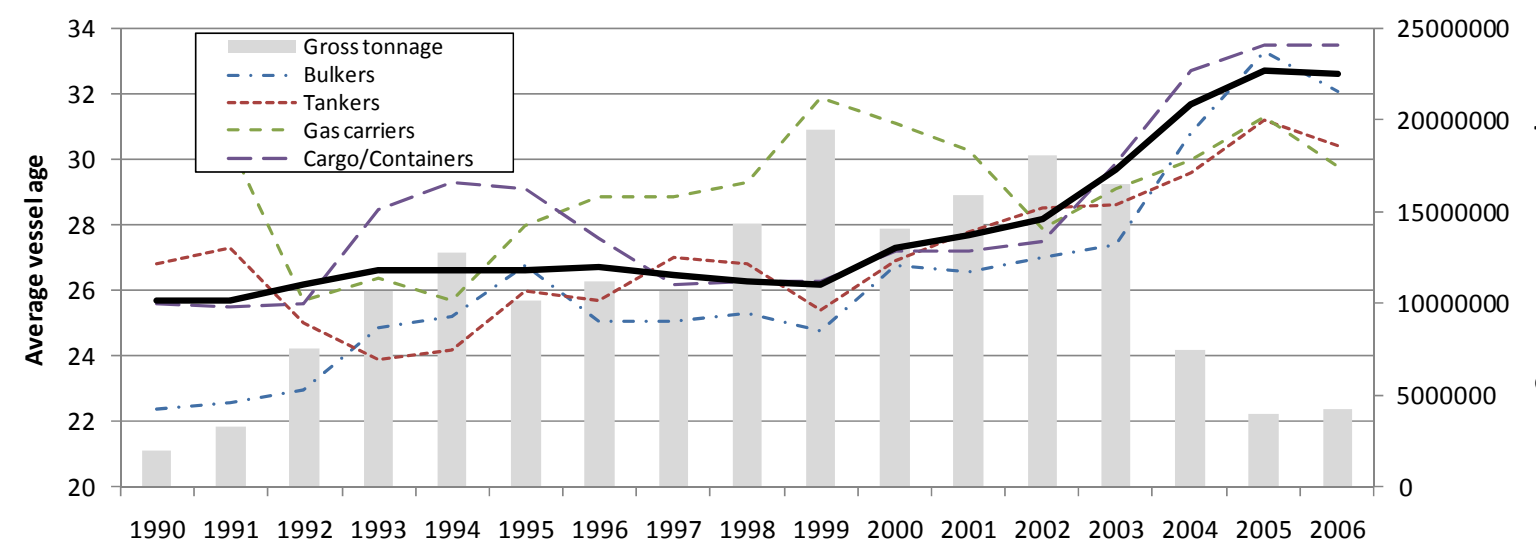

Source: (Mikelis, 2007)

Rates of fleet turnover vary among vessel types and are sensitive to a number of factors beyond simply the age of the vessel. These include amortisation, current and projected operating costs (notably fuel costs), changing market conditions and commercial cycles cost of new vessel construction and steel prices (since owners recover the value of scrapped steel from their vessels). All of these factors can either accelerate fleet turnover or, alternatively, slow it down. For instance, growth across most maritime freight markets in recent years has led to lower rates of scrapping and increased average vessel age. This same growth had led to an upswing in forward orders for newbuilds before the economic slowdown experienced in the second half of 2008. Many of these newbuild orders had been made in a period of rising fuel costs and thus many will likely incorporate fuel-saving technologies and designs (especially those linked to greater economies of scale). As of December 2008, approximately 1400 container vessels were on shipyard order books accounting for a total capacity of over 6 million TEUs - with slightly more than half of this capacity accounted for by large (over 8000 TEU) vessels (CI Online, 2008).

Against this backdrop, rapid deterioration of the economic climate in late 2008 has led to a sharp decrease in container traffic and a relative oversupply of capacity on most container trades which has, in turn, led vessel owners to withdraw vessels from commercial service and hasten scrapping of older ships in late 2008. Depressed GDP growth forecasts and tight credit markets mean that relatively fewer container (or other) vessels will be ordered over the next few years thus retarding the penetration of the most recent fuel saving designs and technologies after the current backlog of newbuilds are delivered. For bulkers and tankers, the precipitously steep drop in charter-party rates (down nearly $97 \%$ from July 2008 to December 2008) has effectively removed much of the short-term incentive for ordering new vessels - again, retarding the penetration of fuel saving designs and technologies. After the initial influx of slightly more fuel efficient vessels on current order books, the market is likely to experience a down cycle with fewer new vessels being ordered and thus lower levels of fuel efficiency technology uptake throughout the world fleet.

Table 4 below outlines aggregate efficiency improvements assumed by Buhaug, $\varnothing$, et al, 2008 for 2020 and $2050^{20}$ according to three vessel categories: ocean-going, coastal and container. Likely efficiency improvements are lower than the maximum potential fuel savings described earlier in this section and are projected to reach $\sim 20 \%$ by 2020 and nearly $50 \%$ by 
2050. These projections also do not account for delayed technology penetration rates as a result of depressed market conditions in 2008-2009.

Table 4. Aggregate Efficiency Improvements (Fleet average values)

\begin{tabular}{llll}
2020 & Low & Baseline & High \\
$\begin{array}{l}\text { Ocean-going } \\
\text { shipping }\end{array}$ & $0 \%$ & $12 \%$ & $22 \%$ \\
$\begin{array}{l}\text { Coastal shipping } \\
\text { Container shipping }\end{array}$ & $0 \%$ & $12 \%$ & $22 \%$ \\
2050 & Low & $21 \%$ & $39 \%$ \\
$\begin{array}{l}\text { Ocean-going } \\
\text { shipping }\end{array}$ & $5 \%$ & Baseline & High \\
Coastal shipping & $5 \%$ & $35 \%$ & $58 \%$ \\
Container shipping & $5 \%$ & $39 \%$ & $65 \%$ \\
\hline
\end{tabular}

Source: Source: Buhaug, $\varnothing$, et al, 2008

3.5 Potential $\mathrm{CO} 2$ reduction from fuel switching for maritime transport

Revisions to MARPOL Annex VI dealing with air pollution from ships will increase the use of alternatives to traditional heavy fuel oil within the shipping sector - principally within coastal areas. It is not clear, though, that operators will switch to low-carbon fuels in order to meet new sulphur content limits and some low-sulphur alternatives may increase overall lifecycle CO2 emissions.

Current heavy fuel oil (HFO) has approximately 3\% sulphur (4.5\% max. permitted) -revisions to MARPOL Annex VI will see the maximum sulphur content go to $3.5 \%$ in 2012 , but most HFO already meets this new limit. BY 2020, sulphur content is set to decrease progressively down to $0.5 \%$. Current sulphur limits applied to Emission Control Areas (ECAs -- North Sea, English Channel and the Baltic now but plans for ECA's in California, USA, Canada and Japan are underway) will be reduced from $1.50 \%$ to $1.00 \%$, beginning on 1 July 2010 , and then on to $0.10 \%$ in 2015. More use of lower sulphur, less viscous fuels such as Marine Diesel Oil (2.0\% sulphur) and Marine Gas Oil (1.5\% sulphur) will likely be necessary to meet these new limits and while these fuels might decrease maritime $\mathrm{CO} 2$ emissions, the full life-cycle $\mathrm{CO} 2$ balance of these fuels, including refining, is positive ${ }^{21}$. If, for instance, these fuels are derived from coal, the balance is assuredly negative. However, the IMO regulations allow for abatement technologies, such as exhaust gas treatment systems and scrubbers which achieve materially identical emission outcomes as the fuel sulphur limits and so the new sulphur content rules do not necessarily mean that large-scale fuel switching will take place.

Use of biofuels (essentially FAME or biocrude) in the maritime sector does not pose any fundamental or insurmountable technology challenges. Ship's large, slow-speed two stroke engines can handle a number of fuel sources (HFO, raw vegetable oils, waste oil, tallow, etc) as long as these comply with specific acidity, viscosity and performance characteristics. Use of biodiesel in marine engines has been trialled in many instances and has been found to be

21 (IMO, 2007) finds that if a global switch to $0.5 \%$ sulphur fuel would lead to a net $2.8 \%-7.3 \%$ increase in emissions once refining impacts are accounted for. 
compatible with marine engines - though increased NOx emissions may result. In the case of vessels running on MDO, blending with biodiesel should be relatively straightforward.

However, while the engines themselves are largely compatible with biofuels, existing HFObased fuel systems will require some modification and/or different operational procedures mainly to avoid the mixing of HFO and biofuels which can lead to precipitate formation and clogging of fuel injectors, centrifuges/filters and fuel lines. Ships may also require separate storage tanks and will require fuel-line and injector pump cleaning when switching from biofuel to HFO or vice-versa. Using pure vegetable oils and biocrude can also lead to deep cavitation in fuel injection pumps (Opdal \& Hojem, 2007) (Opdal, Biodiesel in Car Ferries, 2008).

Biofuels will likely remain more costly than HFO (again, a residual product of oil refining), at least in the short-to-medium run, and operators face little economic incentive to switch under current carbon prices. One promising maritime biofuel whose low quality makes it poorly suited to other uses is Pyrolysis Fuel Oil, or biocrude. This oil can be handled in slow-speed marine engines and could potentially be processed using local biomass near ports though we are not aware of any studies on the impacts of biocrude production on a scale sufficient to fuel the world fleet (Opdal \& Hojem, 2007).

Accounting for the factors described above, Buhaug, $\varnothing$, et al assume that little fuel switching will occur by 2020 (5-10\% LNG) although more fuel switching is assumed to occur by 2050, especially for coastal vessels and tankers: $25-50 \%$ of coastal vessels and $10-20 \%$ of ocean going crude oil tankers are assumed to switch to LNG and up to $20 \%$ of all ships are assumed to switch to synthetic (likely coal-based) diesel.

\subsection{Projected CO2 Emissions from International Shipping}

Drawing on demand forecasts, efficiency improvement assumptions and projected rates of fuel switching, the IMO study projects the following levels of $\mathrm{CO} 2$ emissions from international shipping in 2020 and 2050:

Table 5: CO2 Emissions from International Shipping in 2020 and 2050 under Different IPCC SRES Scenarios (million tonne/yr)

\begin{tabular}{lllllll}
2020 & \multicolumn{2}{l}{$(2007=843 \mathrm{Mt})$} & & & \\
& Low & Baseline & High & Low & Baseline & High \\
A1FI & 770 & 1058 & 1440 & 880 & 2648 & 7228 \\
A1B & 770 & 1057 & 1447 & 885 & 2681 & 7344 \\
A1T & 771 & 1058 & 1447 & 879 & 2668 & 7341 \\
A2 & 740 & 982 & 1275 & 804 & 2194 & 5426 \\
B1 & 734 & 959 & 1252 & 781 & 2104 & 5081 \\
B2 & 719 & 925 & 1160 & 746 & 1903 & 4407
\end{tabular}

Source: Source: Buhaug, $\varnothing$, et al, 2008

According to these projections, despite significant energy efficiency improvements (albeit slowly diffused through the fleet) $\mathrm{CO} 2$ emissions from international shipping would grow by $10-26 \%$ by 2020 and $126-218 \%$ by 2050 under baseline assumptions. Realizing maximum potential efficiency improvements coupled with significant speed reductions and more intensive use of low-carbon fuels can lead to stabilized or slightly decreasing CO2 emissions from international shipping (low estimates) but these developments are unlikely to occur 
without significant changes and interventions. This finding concurs with that of DNV/Lloyd's List (and other studies) which projects that significant reductions in relative efficiency (up to $50 \%$ less fuel consumed per tonne-kilometre for newbuilds in 2050) will only just stabilize maritime CO2 emissions at current (2008) levels given projected increases in maritime trade (Berrefjord, et al., 2008).

The impact of the economic downturn of 2008-2009 will be to reduce overall maritime trade activity leading to lower CO2 emissions than had been previously forecast by Buhaug, $\varnothing$, et al. At the same time, this reduction in activity will likely be accompanied, but not offset, by a slower rate of uptake of fuel efficient technologies and designs due to reduced fleet turnover in the short- to medium-term. Lower oil prices as a result of softening demand will further reduce the fuel efficiency imperative for newbuilds while, at the same time, lowering pressure to implement operational fuel savings. Under the current market and regulatory structure of maritime transport, it is not at all clear that $\mathrm{CO} 2$ reduction imperatives will in any way replace fuel cost imperatives -- it is therefore highly unlikely that maritime fuel efficiency will increase at a higher rate than has been historically observed for the sector absent additional policies. Overall, the $\mathrm{CO} 2$ impact from reduced economic activity will likely more than offset the $\mathrm{CO} 2$ impact from slower uptake of fuel efficient designs and practices. "Business-as-usual" emissions from international maritime transport are likely to track below rather than above baseline projections of the emission forecast ranges detailed in table 5 - especially in the short to medium term (e.g. up to 2020-2030).

\section{International GHG Reduction Policies for Maritime Transport}

Both the international maritime and international aviation sectors have no quantified GHG emission reduction targets under the Kyoto Protocol since no agreed formula has been found for allocating responsibility for emissions among nations rendering the apportionment of burden sharing efforts impossible at present. The two international bodies responsible for these sectors, the International Maritime Organization and the International Civil Aviation Organization have been tasked with elaborating GHG emission reductions strategies for their respective sectors. These efforts are underway within the IMO and a plan should be presented to the UNFCCC COP 15 in 2009 such that maritime emissions are accounted-for under a successor treaty to Kyoto.

One of the difficulties faced by the IMO has been determining both the actual level of emissions from international maritime activity and finding an instrument which allows responsibility for these emissions and for emission reduction efforts to be allocated to nations. The former task has been carried out and the Buhaug, $\varnothing$, et al. report has established a consensus estimate of international maritime CO2 emissions. The second task has proven more difficult for several reasons, not least of which is the complex nature of ownership and control in the maritime sector.

Part of the difficulty encountered within the IMO discussions has been that any global GHGreduction plan established by the IMO might engage nations who currently have no GHG reduction targets under the Kyoto Protocol to accept these for the fleet of vessels under their registry. This, many nations fear, might establish an unwelcome precedent for the overall climate change negotiations being held under the auspices of the UNFCCC and in which the principle of "common but differentiated responsibilities" has been accepted. Indeed, as shown in figure 8, over two thirds of the world's international maritime fleet is registered in countries that have no defined GHG reduction targets. When considering the nationality of the vessel owner, this figure is reversed with about two-thirds of the world's fleet owned by nationals of countries with set GHG reduction targets under the Kyoto Protocol. This finding also holds when considering the vessel operator's nationality. 
Figure 8. World Fleet by Flag and Nationality of Owner and Operator

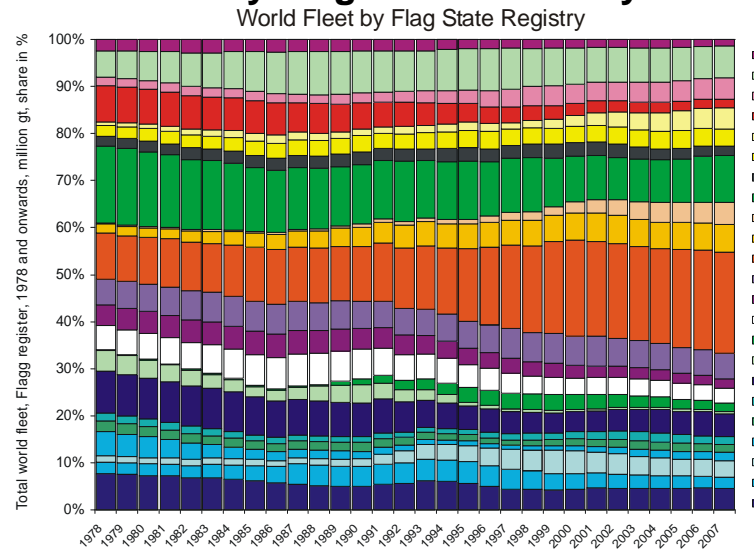

-Mid East

Other Asia

Japan

Hong Kon

Rest of World

Rest of World

¿Marshall isl.

-Bahamas

Other Americas

USA

DOther Europe

Norway (NIS)

Other EU27

Germany

altaly

Malta

Cyprus

World Fleet by Vessel Ownership Nationality

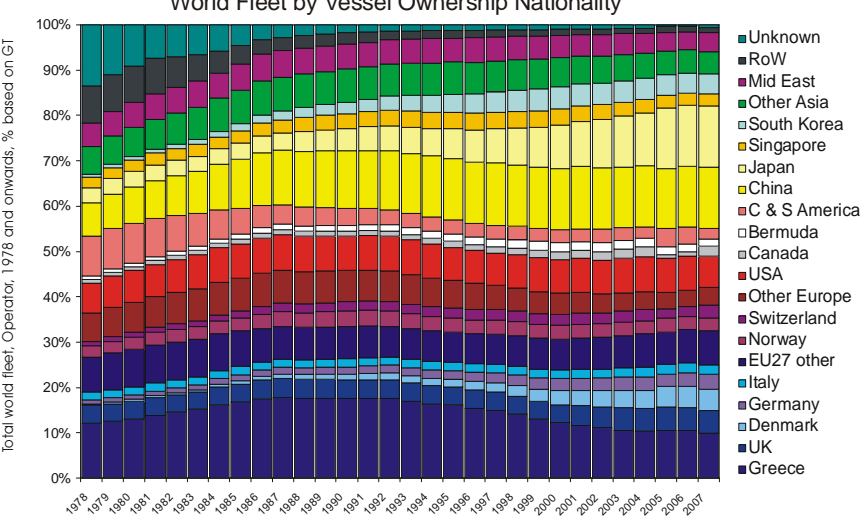

World Fleet by Vessel Operator Nationality

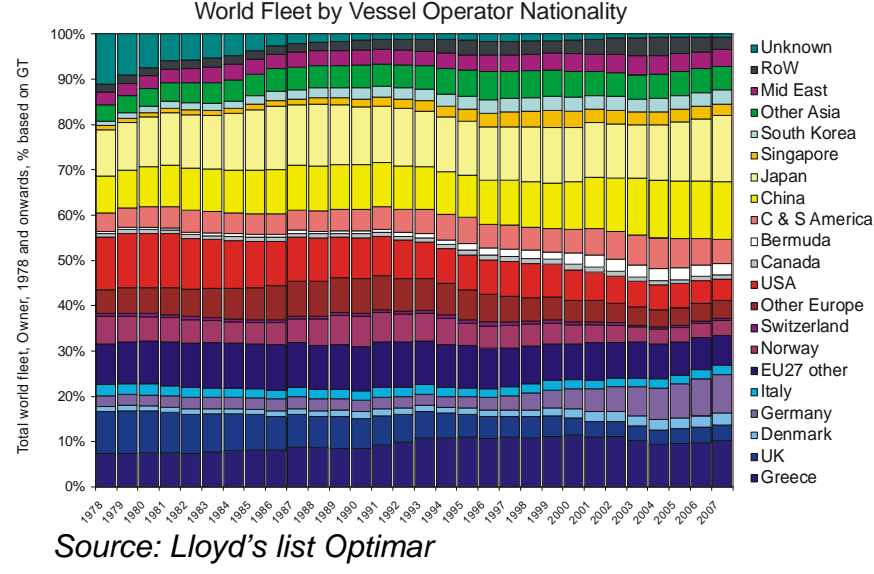

\subsection{IMO Energy Efficiency Design Index}

At present, the IMO is considering several instruments which might comprise its contribution to the post-Kyoto climate regime.

The first of these is the creation of an Energy Efficiency Design Index (EEDI) for new vessels. As currently proposed, the design index would represent a minimum design standard in terms of energy efficiency (and a maximum design standard in terms of CO2 emissions) by vessel type and unit of work (tonne/mile). It would essentially be analogous to the road vehicle fuel efficiency standards in force in a number of countries with the difference that it would measure energy use per tonne/mile rather than per vehicle/mile. The design 
index would allow transparent comparison of energy use (and, indirectly, $\mathrm{CO} 2$ emissions) amongst like vessels, and would set a minimum benchmark that could be periodically revisited in order to reduce overall maritime energy use.

Initial trials of an early form of the IMO Energy Efficiency Design Index show that energy expenditure for vessels of similar size (expressed in gross tonnes) can vary significantly thus revealing some room for improvement (figure 9). Vessel design was not found to be the only source of variation, however, and other factors such as cargo requirements and loading, speed, length of empty (ballast) return or repositioning trips, ship condition and maintenance and weather and currents will all either have to be normalised or otherwise accounted for in the index (Buhaug $\varnothing ., 2008$ ).

Because of the reticence some countries have in deviating from the "common but differentiated responsibilities" principle mentioned earlier, the possible mandatory nature of the EEDI has led to considerable resistance. However, diluting the reach of the proposed index and rendering it mandatory only for Annex 1 countries would considerably weaken the instrument as over two-thirds of the world's registered fleet would no longer come under its scope.

Other difficulties facing the adoption of the EEDI are related to what should be covered (e.g. should it allow for different auxiliary power requirements and how might it account for different vessel duty cycles) as well as to the metrics to be used (deadweight, gross tonnage, cargo volume, TEU capacity for container vessels, etc?). At present, it is not clear what form the final EEDI will have and whether or not it will become a mandatory or voluntary instrument for non-Annex 1 countries.

While the EEDI shows some promise as a way to reduce $\mathrm{CO} 2$ emissions from newbuilds, it would do nothing to reduce emissions from vessels currently in operation and, given long average vessel life, would only have a noticeable impact over the medium to long term. 
Figure 9. CO2 index and gross tonnage for ship groups, Average and individual observations

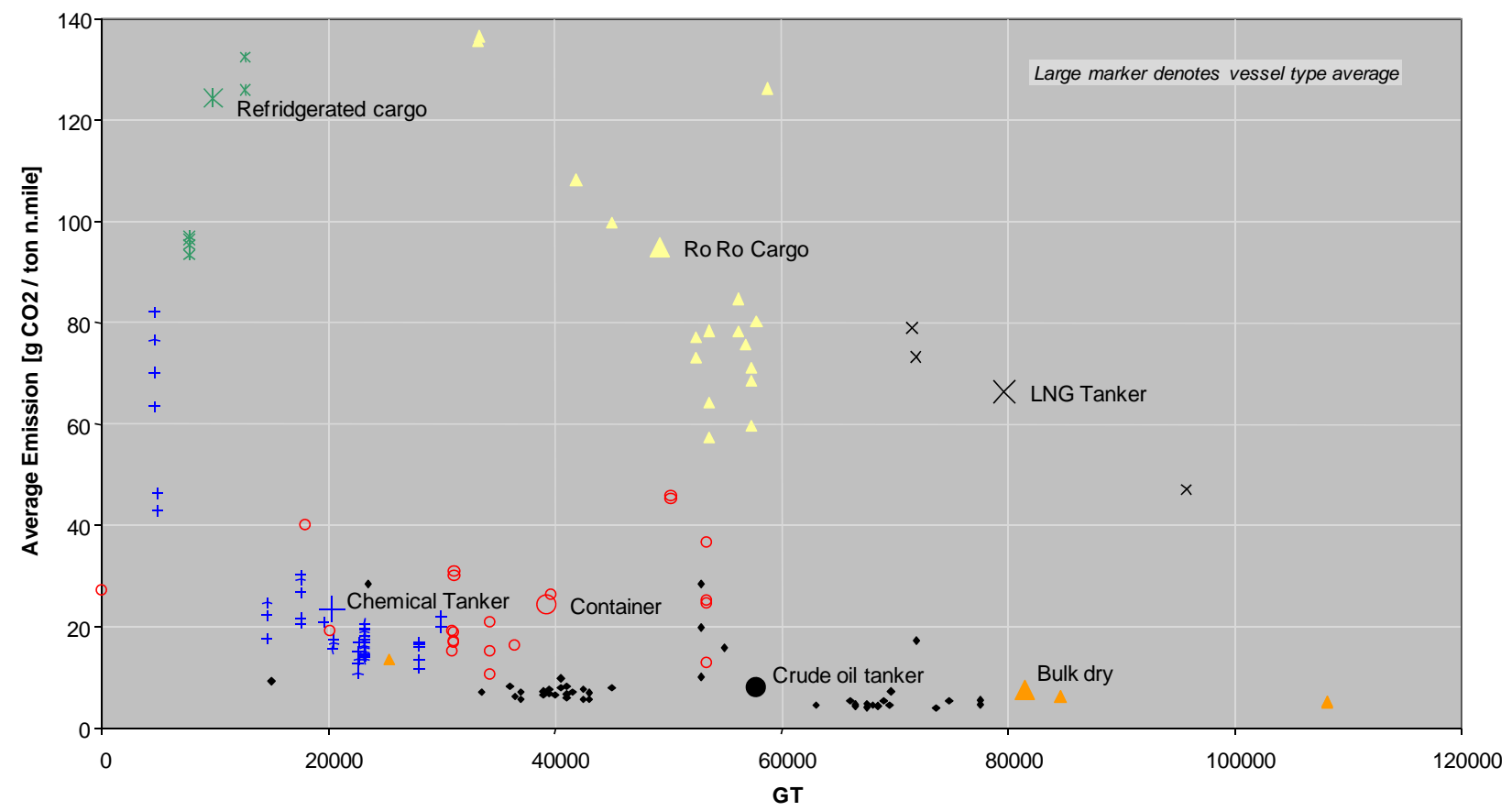

Source: Adapted from (Buhaug Ø. , 2008)

\subsection{Voluntary Energy Efficiency Operational Index}

In order to address emissions from existing vessels, the IMO is in the process of updating a set of best-practice measures for operational fuel savings and $\mathrm{CO} 2$ emission reductions. This index would allow vessel owners, operators, shippers and administrations to benchmark individual vessel and company performance. While some national administrations might render the operational index mandatory for their flagged vessels, it will likely not be adopted as such by the majority of the world's flag states and as such will probably only have a relatively limited impact. Nonetheless, it could represent one way for administrations to differentiate treatment of vessels based on their emission profiles (e.g. through port fees, $\mathrm{CO} 2$ fee rebates or other incentive-based instruments).

\subsection{Other International Measures}

Also under early stages of discussion within the IMO are economic and market-based instruments such as a global fuel levy or including maritime CO2 emissions within a cap-andtrade system. Kågeson presents these options more fully in a companion paper (Kågeson, 2009).

Discussions on either a global levy or a maritime emission trading scheme have not advanced much because for these instruments to be effective, they would have to be global in nature and many countries have made it clear that they are uncomfortable with taking on an equivalent GHG reduction burden as Annex I countries regardless of the sector under consideration. It may very well be that some countries might prefer to address these issues in the maritime sector separately (and after) the forthcoming COP15 in order to preserve their negotiating positions. 
While a global levy might be procedurally simpler to put into application, its administration and determining how its proceeds should be allocated are daunting challenges. Lessons from the redistribution of other transport taxes and levies would argue for these funds being put back into the maritime sector and, in particular, being applied directly to the further reduction of $\mathrm{CO} 2$ emissions and energy use.

Including maritime emissions within a cap-and-trade system would also face considerable difficulties on a global basis - not least of which is the absence of a global CO2 trading scheme. However, such an approach, especially if it included maritime emissions within a broader cross-sectoral trading system, might allow for an influx of money to the sector if lessons on the marginal abatement costs of other pollutants from maritime activity hold true for $\mathrm{CO} 2$ emissions ${ }^{22}$. Crucial for this option to succeed would be the manner in which existing and planned trading schemes allow for cross-trading - if the ETS, and proposed Australian, Californian, Western US States, British Columbia, New Zealand and United States initiatives were to allow for cross-trading, then a quasi-global carbon might exist rendering the inclusion of maritime emissions easier. Nonetheless, determining the exact allocation of emissions (to Flag states? to vessel owners? To vessel operators?) and the allocation method (auctioning, grandfathering, etc...). Given the inherent difficulties in both of these approaches, it is likely that an international consensus (or at least a broad regional consensus) will be necessary for either of these approaches to be adopted following COP 15.

\subsection{Regional measures}

The maritime sector is a truly global industry and regulating its $\mathrm{CO} 2$ emissions only truly makes sense at the global level by the IMO. Nonetheless, there are very real tensions within the IMO as to how fast, how far and how wide to go in reducing maritime $\mathrm{CO} 2$ emissions. This has led to several countries and country groupings to evoke the option of unilateral action. Foremost among these has been the European Union which has publicly stated that unless it is satisfied with progress on reducing $\mathrm{CO} 2$ emissions within the IMO, it will unilaterally act to include maritime $\mathrm{CO} 2$ emissions from vessels travelling to and from its ports within the EU ETS. This is a credible threat given that the EU has already acted unilaterally to include international aviation emissions within the ETS. It is conceivable that the precedent of regional action to impose low-sulphur emission areas under the IMO framework might be repeated with regions being allowed to set up low $\mathrm{CO} 2$ emission areas under some agreed IMO framework - but this is far from an optimal solution and one that has not yet even been discussed within the IMO.

Another option for regional action would be for states to allow for CO2-differentiated harbour dues or to implement some form of CO2-based emission charge, possibly with some rebating, to favour low-emitting vessels and operators. The IMO CO2 design index and the voluntary $\mathrm{CO} 2$ operational index could serve as the basis for differentiation - but how to account for vessels that do not participate in the latter? Also, as with a levy system, how and where the revenue will be used will important in determining the instrument's global impact. Were the revenue used to reduce emissions from vessel operations and newbuilds throughout the world fleet, the impact might be greater than if the revenue were put into the general budget - but how to finance these improvements in non-national fleets?

22

For instance, the marginal abatement costs of NOx emissions have been shown to be considerably less from maritime sources than from land-based sources - principally because the latter have been increasingly regulated while the former have not. Similar low $\mathrm{CO} 2$ abatement costs may exist for maritime emissions when compared to more regulated land-side emissions. 


\section{Sources}

Berrefjord, P. M., Endresen, Ø., Simonsen, B. C., Behrens, H., Alvik, S., Reynolds, G., et al. (2008, July). CO2 Emissions from Shipping - Technical and Operational Options for Emission Reduction. IMO MEPC 58/INF.14 . IMO - DNV/Lloyds Register.

Bond, P. (2008, October 23). Improving fuel efficiency through the supply chain and the ship efficiency management plan. Presentation made to: $x x x x$. to fill in: Interorient - Cyprus Chamber of Shipping.

Buhaug, $\varnothing$. (2008). Assessment of CO2 emission performance of individual ships: The IMO CO2 index. (Marintek, Éd.)

Buhaug, Ø., Corbett, J. J., Endresen, Ø., Eyring, V., Faber, J., Hanayama, S., et al. (2008, September 1). Updated Study on Greenhouse Gas Emissions from Ships: Phase I Report. London, United Kingdom: International Maritime Organization.

Cl Online. (2008).

Corbett, J. J., Wang, H., \& Winebrake, J. J. (2009). The Impacts of Speed Reductions on Vessel-based Emissions for International Shipping. Paper submitted to the US Transportation Research Board's annual meeting . US Transportation Research Board.

Green, E. H., Winebrake, J. J., \& Corbett, J. J. (2008, July 30). Opportunities for Reducing Greenhouse Gas Emissions from Ships. IMO MEPC 58/INF.21.

Hobson, M., Pell, E., Surgand, M., Kollamthodi, S., Moloney, S., Mesbahi, E., et al. (2007, March). Low Carbon Commercial Shipping. AEA Energy and Environment, Newcastle University.

IMO. (2007). BLG 12/INF 10.

IMO. (2007, December 28). Report on the analysis of impacts on global refining and CO2 emissions of potential regulatory scenarios for international marine bunker fuel. Review of MARPOL Annex VI and the NOx Technical Code, IMO/BLG 12/INF.11. (N. C. EnSys Energy and Systems, Éd.) LOndon: International Maritime Organization.

Kågeson, P. (2009, May). Environmental Impacts of International Transport: Making International Transport Pay its Climate Bill. Paper submitted to the 2009 International Transport Forum Ministerial meeting . (S. S. Nature Associates, Éd.) Leipzig: International Transport Forum.

MAN Marine. (2007). Basic Principles of Ship Propulsion.

Mikelis, N. E. (2007, September). A Statistical Overview of Ship Recycling. Paper presented to the International Symposium on Maritime Safety, Security and Environmental Protection . Athens.

Ocean Policy Research Foundation. (2008, May). The World's Changing Maritime Industry and a Vision for Japan. Tokyo, Japan. 
Opdal, O. A. (2008, June). Biodiesel in Car Ferries. A feasibility study on the use of biofuels in Norwegian domestic ferries . Oslo: Zero Emission Resource Organization.

Opdal, O. A., \& Hojem, J. F. (2007, December). Biofuels in Ships. A project report and feasibility study into the use of biofuels in the Norwegian domestic fleet . Oslo: Zero Emission Resource Organization.

Stopford, M. (2009). Maritime Economics (3rd Ed.). London: Routledge.

Torvanger, A., Bogstrand, B., Skeie, R., \& Fuglestvedt, J. (2007, December). Climate Regulation of Ships. CICERO Report 2007:7 . Oslo, Norway: Center for International Climate and Environmental Research.

Wang, C. J. (2007, December 1). Spatial Representation of Global Ship Emissions Inventories. Environmental Science \& Technology .

Wang, H. (2009). GHG Marginal Abatement Cost and its Impacts on Emissions per Import Value from Containerships in the United States. Discussion Paper. Marine Policy Program, University of Deleware.

Wartsila. (2008). Boosting Energy Efficiency.

Wettstein, R., \& Brown, D. (2008, June). Derating: A Solution for High Fuel Savings and Lower Emissions. Winterthur: Wartsila Switzerland Ltd. 